\title{
Geomorphic study of fluvial landforms on the northern Valles Marineris plateau, Mars
}

\author{
N. Mangold, ${ }^{1}$ V. Ansan, ${ }^{1}$ Ph. Masson, ${ }^{1}$ C. Quantin, ${ }^{1,2}$ and G. Neukum ${ }^{3}$ \\ Received 10 August 2007; revised 25 February 2008; accepted 2 April 2008; published 9 August 2008.
}

[1] Fluvial landforms are observed on the plateau near Echus Chasma and other locations on the Valles Marineris plateau using high resolution (10 to $50 \mathrm{~m} / \mathrm{pixel}$ ) Mars Express images and topography. Branching valleys have a 20 - to $100-\mathrm{m}$ deep V-shape profile typical of fluvial processes. Their incision occurred in a thin $(<150 \mathrm{~m})$ and weak, dark unit that overlies the plateau basement. The valleys are distributed close to watershed boundaries as expected for overland flows, and different from pure glacial or hydrothermal processes. The $2 \mathrm{D}$ geometry of valley networks show drainage densities reaching $1.3 \mathrm{~km}^{-1}$ that indicate a strong $2 \mathrm{D}$ extension stage that usually requires a minimum of thousands of years, as established from terrestrial examples. However, the 3D valley geometry shows a limited incision, and a lack of concavity, suggesting a limited development in time (millions of years of evolution are unlikely). Many outlets connect to the heads of canyons of Echus Chasma that might involve sapping processes. These canyons might have formed coevally with shallow valleys: their difference in geometry is a consequence of the difference in lithology which induced a difference in the erosion capacity, and an enhanced infiltration conducing to sapping. Valleys are submitted to modification by aeolian processes, sometimes leading to the formation of inverted channels as observed more broadly through the region. These landforms formed late in the Early Mars history and might be considered as examples of episodic fluvial events due to short-term climate changes and/or regional fluvial activity after the Noachian.

Citation: Mangold, N., V. Ansan, Ph. Masson, C. Quantin, and G. Neukum (2008), Geomorphic study of fluvial landforms on the northern Valles Marineris plateau, Mars, J. Geophys. Res., 113, E08009, doi:10.1029/2007JE002985.

\section{Introduction}

[2] Understanding the nature and origin of fluvial landforms is important for explaining the geological and climatic evolution of Mars. The presence of liquid water at some time in Mars past is now accepted, but there is debate over whether the origin of the water is from subsurface or atmospheric origin [Pollack et al., 1987; Clifford, 1993; Carr, 1996; Baker, 2001]. Indeed, most admit that ancient valleys were formed by fluvial flows, but whether their formation had either a groundwater origin through hydrothermal heating and sapping, or a surface origin through rainfall or snowmelt is debated [Pieri, 1986; Brakenridge et al., 1985; Baker and Partridge, 1986; Carr, 1996; Baker, 2001; Grant, 2000; Gulick, 2001; Craddock and Howard, 2002; Carr and Head, 2003; Mangold et al., 2004; Harrison and Grimm, 2005; Ansan and Mangold, 2006]. A similar controversy now exists for the formation of the recent gullies observed in MOC (Mars Observer Camera) images as they might have formed by flows emerging from aquifers or surficial ice melting [e.g., Malin and Edgett,

\footnotetext{
${ }^{1}$ Laboratoire IDES, Université Paris-Sud and CNRS, Orsay, France.

${ }^{2}$ Now at Laboratoire Science de la Terre, Villeurbanne, France.

${ }^{3}$ Freie Universität, Berlin, Germany.
}

Copyright 2008 by the American Geophysical Union. 0148-0227/08/2007JE002985
2000; Costard et al., 2002]. Whereas the formation of recent gullies does not invoke a denser atmosphere, ancient valleys are much more developed landforms that are found mainly in the Noachian highlands $(>3.7 \mathrm{Ga})$, and they are usually interpreted as evidence for a denser past atmosphere [Carr, 1996]. Younger valleys of apparent fluvial origin were also observed in the Hesperian terrains and several are even found in the Amazonian regions [Carr, 1996]. The association of some of these late valleys with volcanoes in Alba Patera or Appollinaris Patera led many authors to invoke geothermal heating and volcanism as a triggering mechanism for these valleys [Gulick and Baker, 1989; Gulick, 2001; Dohm and Tanaka, 1999; Carr and Head, 2003]; a view reassessed recently using new data sets [Fasset and Head, 2006]. The identification of dendritic valleys attributed to surface runoff in the Hesperian terrains of the Valles Marineris plateau suggests that a climatic origin was still possible during or after this period [Mangold et al., 2004]. However, this interpretation leads to some unsolved questions: How are sapping canyons and valleys correlated? Why are these valleys restricted to small regions as opposed for being more widespread? How long did conditions persist in the formation of these landforms? Under what kind of climatic conditions did the valleys formed? We discuss these questions through the detailed study of fluvial landforms situated on the plateau of the Valles Marineris region 
using new data of the High Resolution Stereo Camera (HRSC) of the Mars Express (MEx) mission.

[3] We focus our study on two primary areas, the plateau west of Echus Chasma and the plateau west of Juventae Chasma, and discuss more briefly other potential areas of interest (Figure 1). In the Echus Chasma region, the HRSC instrument provides the coverage and resolution to improve previous observations. We quantify the geometry of valleys using DEM (Digital Elevation Model) calculated using the stereoscopic images. In Juventae Chasma, we identify and discuss sinuous lineations that may be caused by the erosion of valleys. We discuss the different interpretations of these landforms and their implication for the hydrological activity on Mars. Our major goals are to detail the geometry of valleys relative to lithology and postvalley erosional landforms.

\section{Data}

[4] The data we used in conducting our study consists mainly of new HRSC images [Neukum and Jaumann, 2004]. The HRSC images with nadir resolution at $12 \mathrm{~m} /$ pixel on orbits 97, 920, and 2204 allow for a thorough study of the morphology and geometry of the valleys and detailed mapping (Figure 2). Gray scale images have better resolutions than the color or stereo images. We used a triplet of the HRSC images acquired on the orbit 2204 to generate the HRSC DEM (Digital Elevation Model) using the DLRBerlin tools developed for the mission [Scholten et al., 2005; Gwinner et al., 2005]. Each image triplet consists of a nadir and two stereo images. A total of 2,108,364 homologous points have been extracted from these data in the area between $2^{\circ} \mathrm{N}$ and $1.5^{\circ} \mathrm{S}$ of latitude. These points have been projected onto the Mars datum [Duxbury et al., 1999] using a sinusoidal projection at a spatial gridding of $50 \mathrm{~m}$, with a resulting statistical height accuracy of $54 \mathrm{~m}$ [Ansan et al., 2007, 2008]. This height accuracy is a statistical error over the whole region. In locations where the homologous points used by the software are dense, this accuracy improve to $20 \mathrm{~m}$ or better. Details describing the processing are presented in a companion paper by Ansan et al. [2008]. Two other orbits (97 and 920) were also computed by the same method but the lower image quality and orbital parameters resulted in fewer homologous points and less accuracy, so these data were not used. In the Juventae Chasma region, we use the image acquired on the orbit 243 but the landforms studied are smaller than the resolution of the topography.

[5] MOC images (www.msss.com/moc_gallery) from the Mars Global Surveyor (MGS) mission and THEMIS images (http://themis-data.asu.edu) were also used to complete this study. THEMIS Infrared (IR) images [Christensen et al., 2003], especially the nighttime images, were used as a qualitative indicator of the thermo-physical properties of the surface (e.g., presence of dust/sand/rocks).

\section{Geomorphic Characteristics of the Fluvial Landforms}

\subsection{Overview of West Echus Chasma Plateau Landforms}

[6] The plateau west of Echus Chasma displays a large number of shallow and sinuous valleys that branch together to form dendritic valley networks systems (Figure 2). Echus Chasma is the source area of Kasei Valles, one of the Late Hesperian outflow channels flooding into Chryse Planitia [e.g., Scott and Tanaka, 1986]. The Echus Chasma depression was subsequently filled by Amazonian lava flows [e.g., Scott and Tanaka, 1986]. Deep tributary canyons dissect the plateau and connect to the Echus Chasma at various locations. These canyons display a branching pattern with locally sinuous shapes and steep walls with amphitheater canyon heads. These characteristics are typical of sapping canyons such as Louros Valles located south of Ius Chasma [Higgins, 1982; Lucchitta et al., 1992]. Sapping is thought to be related to the backward incision of canyons due to circulation and seepage groundwater [e.g., Laity and Malin, 1985]. We distinguish these two distinct types of fluvial landforms by referring the valleys observed on the plateau as "shallow valleys", and the deep and narrow sapping-like valleys branching from the Echus Chasma as "tributary canyons".

[7] A series of parallel faults cross the plateau at the southern edge of the study area. These faults trend $\mathrm{E}-\mathrm{W}$ at the bottom left part of the Figure 2 and change orientation to $\mathrm{NE}-\mathrm{SW}$ at the bottom right. These structures are straight with a small topographic drop, which is typical of normal faults. These normal faults likely belong to the extensional episodes of faulting that occurred throughout the history of the Valles Marineris region [e.g., Wise et al., 1978]. Other tectonic patterns, such as wrinkle ridges, are almost absent in this region.

[8] Fluvial landforms on this plateau display different characteristics from place to place that we describe using HRSC and MOC images: (1) the central area contains valleys that are clearly visible and are dendritic (Figures 3 and 4); (2) the area immediately north of this area has much higher albedo and contain apparently few valleys (Figure 5); (3) the area immediately southwest of the central area contains valleys that interact with faults (Figure 6); (4) the region west of the central area and west of the long tributary canyon (Figure 7); (5) in addition to the regions shown in Figure 2, a small area at the northern end of the plateau contains valleys that are also visible along the Echus Chasma (Figure 8). Finally, similar valleys are also observed south and east of the Echus Chasma (Figure 9).

\subsection{Shallow Valleys of the Central Area of West Echus Plateau}

[9] Valleys form a dendritic pattern at the kilometer scale in the HRSC nadir image (Figures 3 and 4). Close views in MOC images show that the shallow valleys are filled by bright material that form dunes (Figure 3c). Small dunes are spaced $<100 \mathrm{~m}$ apart and display a parallel trend typical of wind blown material. These bright dunes almost completely blanket the valleys to the left side of Figure 3d, as seen in the MOC close-up (Figure 3e). Figure $3 e$ shows a valley almost completely filled by aeolian material. These observations indicate that many valleys on the center of the plateau are accentuated by albedo differences caused by material covering the valley floors. The shallow valleys located in Figure 4 are visible primarily because of their relief. A careful observation of MOC images show the presence of aeolian filling too (Figure 4b), but more locally and less developed than in the previous examples (Figure 3) 


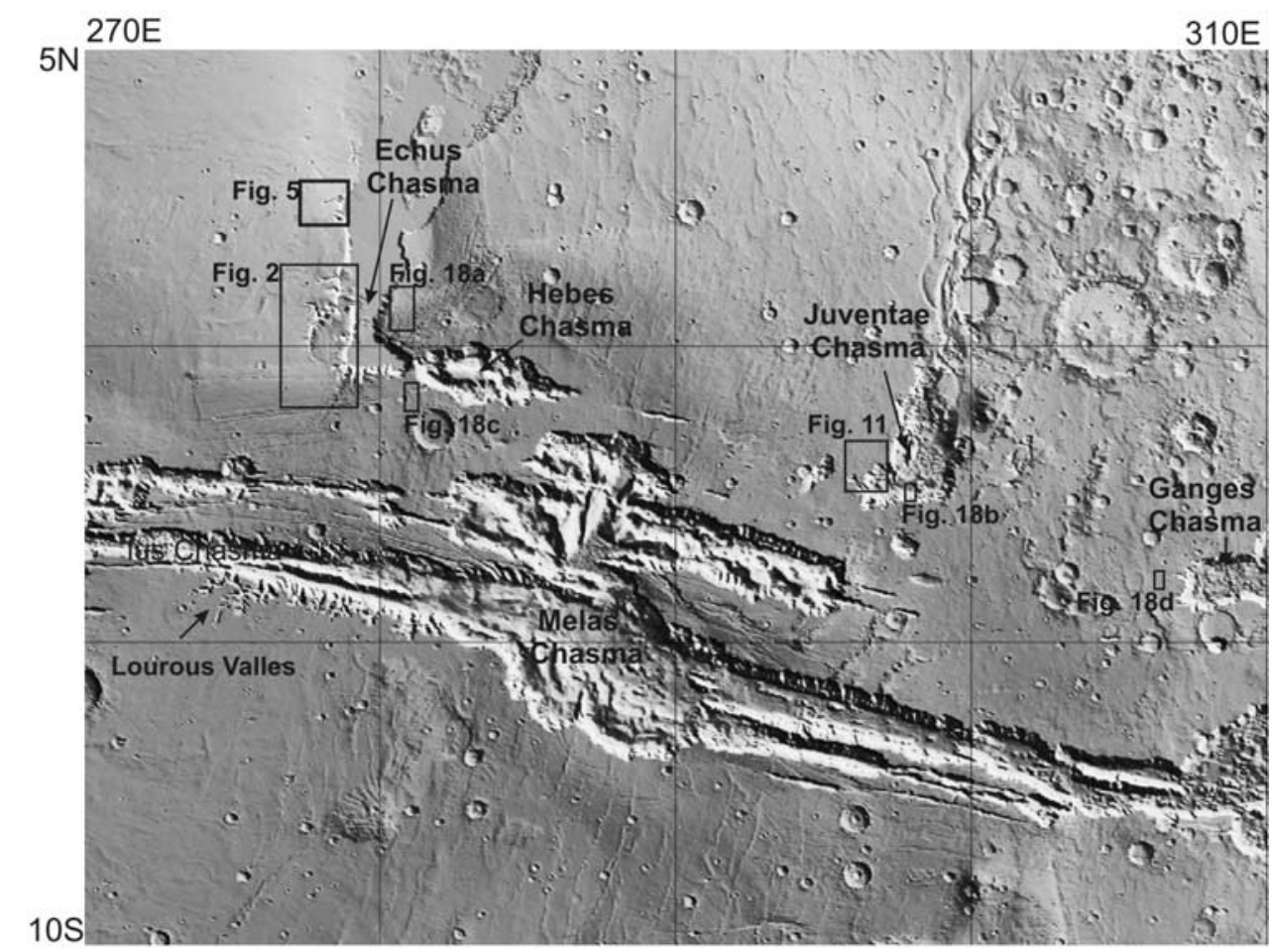

Figure 1. MOLA shaded relief map of the Valles Marineris region showing the location of the areas studied.

suggesting that they are always identified by albedo differences alone.

[10] Most of the shallow valley systems are dendritic with many branching tributaries (Figures 3 and 4). The largest valleys are typically $1 \mathrm{~km}$ wide and a few tens of km long, and many are sinuous. Smaller tributaries are visible for most main valleys but the smallest ones are often difficult to follow because they are filled discontinuously by a bright aeolian blanket. Most of the valleys do not show inner channels or braiding at the HRSC scale that could indicate a dynamic of flow, but the burial of valley floors by aeolian material could mask small fluvial landforms such as these. One possible exception is the valley located at the top right of Figure $3 \mathrm{~d}$. It shows a sinuous shape with local evidence of braiding.

[11] Many major shallow valleys connect directly to the heads of sapping canyons (Figure $3 \mathrm{a}$ and $3 \mathrm{~d}$ ). In Figure 3a, the connection is separated by an undissected interfluve that is few kilometers of a plateau that is not incised. Nevertheless, the presence of a few residual buttes of dark material located at the edge of the canyon scarp suggests erosion removed some of the plateau material here (Figure 3b). These observations suggest that shallow valleys and tributary canyons were not always disconnected, as evidenced by similar topographic lows in this location. On the other hand, a few valleys are cut by two branches of sapping canyons (Figure 4a, bottom left), suggesting canyons erosion continued after valley networks formed. These two canyons are aligned into a $\mathrm{E}-\mathrm{W}$ direction to the tectonic faults located toward the West, at the difference of other tributary canyons, which are more sinuous and do not follow the faults direction.

[12] Canyon wallslopes show that small valleys incise into a dark material overlying the rocky wallslopes (Figure 4c).
Wallslope material is likely composed of lava flows like the Valles Marineris plateau [e.g., Lucchitta et al., 1992]. This upper dark material is indicated by the double arrows in Figures $4 \mathrm{c}$ and $4 \mathrm{~d}$. Valleys incise into this upper dark unit, but no valley incision is visible in the wall rock itself. This observation is valid for all MOC images studied. For example, Figure $3 \mathrm{~b}$ shows that the canyon head wallslope is not dissected by any valley. Thus the observations of eroded plateau with some dark residual hills (Figure $3 \mathrm{~b}$ ) and outcrops of wallslopes covered by dark material (Figure 4c) suggest valleys formed into an upper unit on the plateau that is darker and weaker than the plateau basement which is probably composed of a series of lava flows.

\subsection{Valleys North of the Central Area}

[13] The region north of the central area appears devoid of shallow valleys using the image contrast of Figure 2. However, after an image enhancement, many patterns are visible which look like old incision by branching valleys (Figure 5). Indeed, these patterns are perpendicular to the canyon borders, and therefore parallel to the local slope. These landforms cover the entire plateau and are not localized on a specific area of the image. A MOC closeup in a valley (Figure 5c) shows a surface that appears depleted of impact craters and smooth at the tens of meters scale, which is best explained by a dust mantle that has buried the underlying landforms. This might explain the bright homogeneous tone of that area and the smooth texture. This observation also suggests that valleys visible primarily in the area west of the Echus Chasma extend northward below a mantle of dust (Figure 5). This interpretation is also supported by the darkness of the THEMIS 

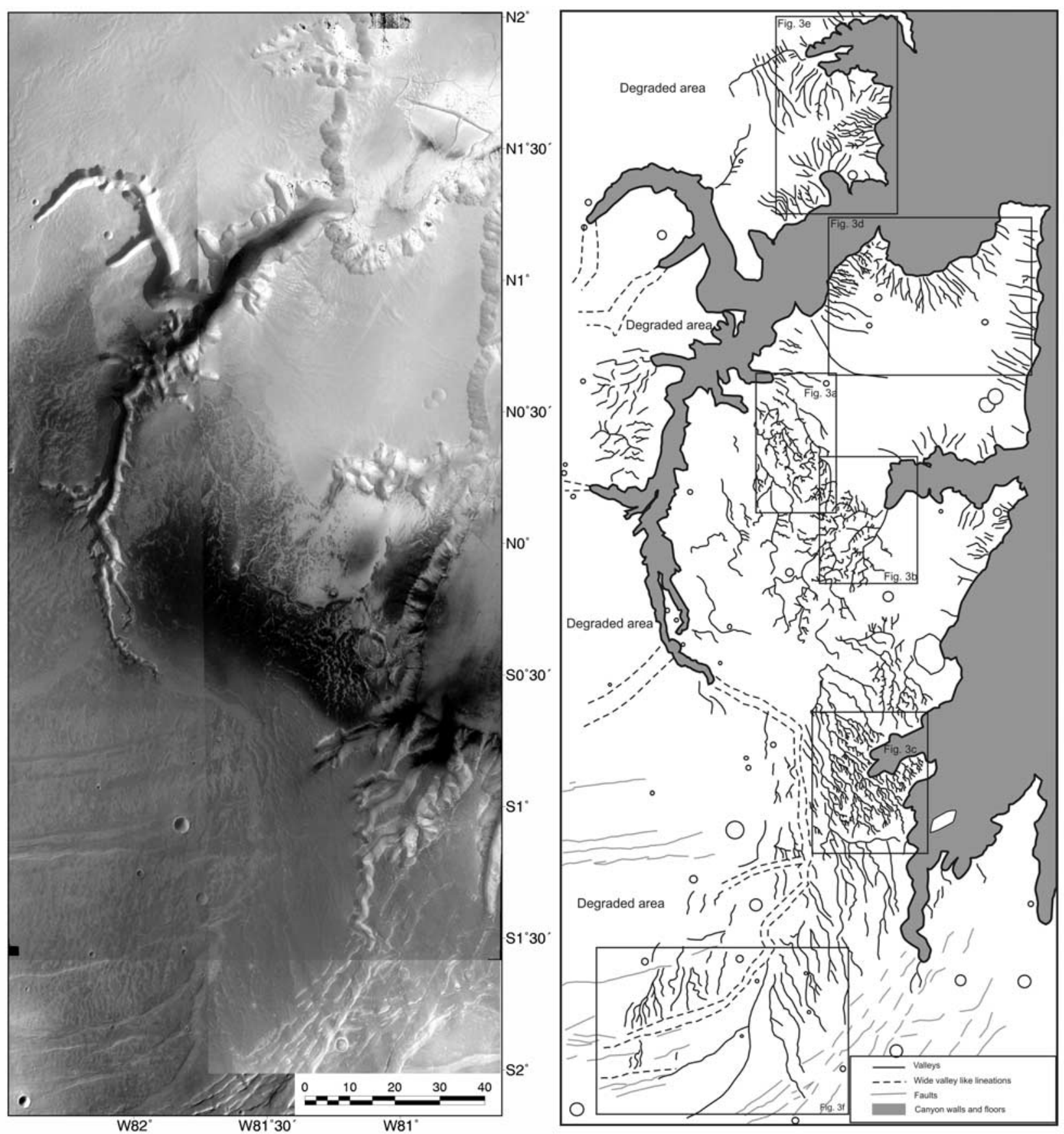

Figure 2. (a) Mosaic of two HRSC images 920 and 97 on the West Echus plateau. (b) Geomorphic map of fluvial landforms.

nighttime IR images, which is interpreted as dust or fineparticle material that is cold at night. This thick blanket prevents any quantitative analysis of the fluvial characteristics of these features.

\subsection{Valleys Southwest of the Central Area}

[14] Southwest of the central area, many valleys are visible, but they appear less dense and are more difficult to examine than in the central area (Figure 6). In contrast to those of the central area, valleys are apparent because of their topography rather than aeolian filling which appears limited here (Figure 6b). These valleys incise into a dark material similar to that of the central area. They have the same characteristics as in the central area, but most of them display a $\mathrm{N}-\mathrm{S}$ subparallel pattern rather than a pure dendritic pattern with orthogonal junctions, suggesting that they may be controlled by $\mathrm{E}-\mathrm{W}$ faults. These valleys trend almost orthogonally to the regional slope due to the local changes in slope created by the faults.

[15] The relationship between valleys and $\mathrm{E}-\mathrm{W}$ faults is complex. Most valleys have a $\mathrm{N}-\mathrm{S}$ direction corresponding to the regional slope as in the central region. These valleys 

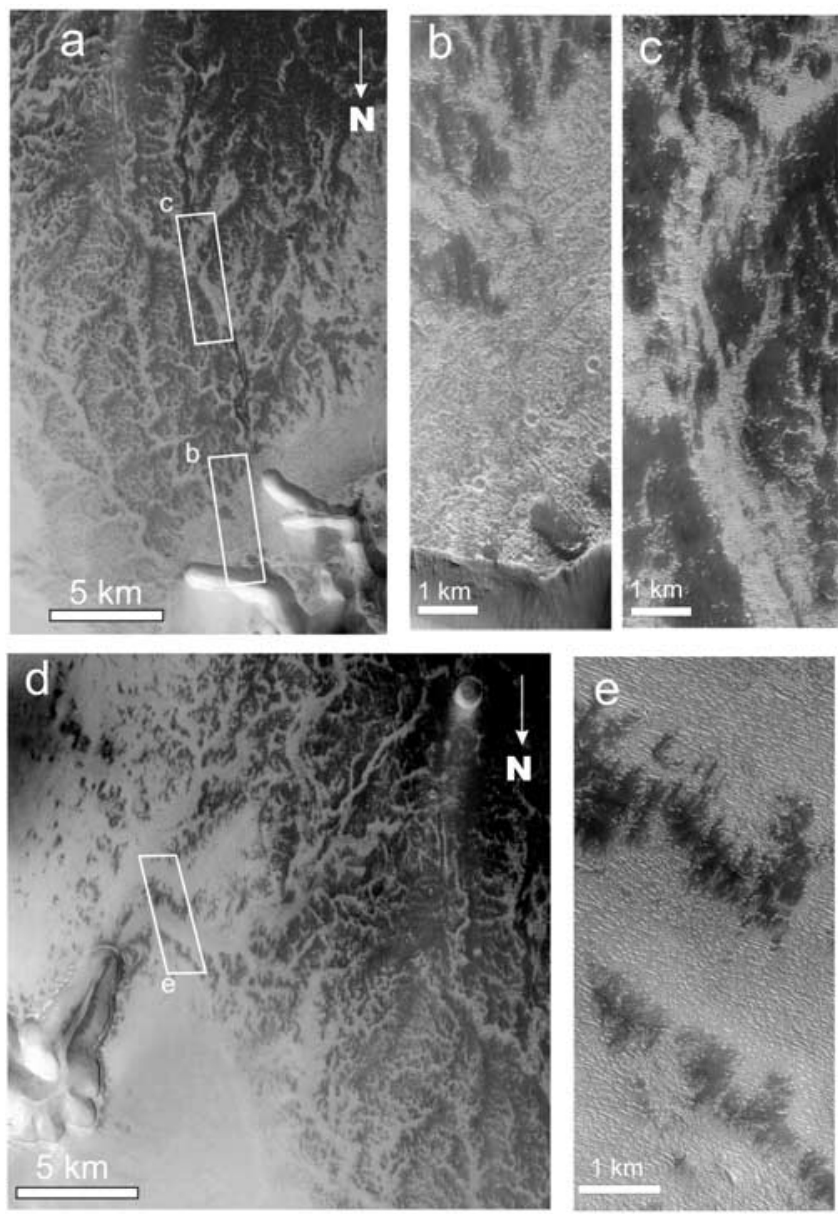

Figure 3. (a) Close-up from an HRSC image 97 on the West Echus plateau showing small sinuous landforms interpreted as branching valleys that have incised into a dark tone material. Major tributaries of these valleys seem to connect to canyon heads. (b and c) Close-up of MOC E1400967 over Figure 3a. Figure 3b shows the plateau edge with a residual butte of dark material (bottom right). Notice the lack of incision by valleys of the canyon wall. Figure $3 \mathrm{c}$ shows a valley filled by light tone material containing small ridges, which is interpreted as an aeolian infill. (d) Another HRSC image over dendritic patterns of valleys. Note that the main tributary connects to the canyon head. (e) Close-up of a MOC image in Figure 3d. Aeolian infill of the valley close to the outlet with small ripple-dunes visible at the $100 \mathrm{~m}$ scale.

connect to main tributary valleys that have a $\mathrm{W}-\mathrm{E}$ trend at the foot of some of the fault scarps (Figure 6a). The E-W trending valleys are controlled by the tectonic pattern. An exception is a valley to the east, which cuts fault scarps and follows the $\mathrm{N}-\mathrm{S}$ direction of the regional slope (bottom of Figure 6a). These relationships indicate that many shallow valleys formed after the plateau had experienced faulting. Local crosscuttings of faults over valleys show the reactivation of several faults after the final episodes of valley formation (for example bottom right of Figure 6a). Additionally, many faults look fresh and are not eroded by the fluvial activity. Thus the period of time of the tectonic activity likely encompasses the period of fluvial erosion.
[16] In addition to the shallow valleys, a few elongated landforms resembling usual fluvial valleys also cross this area. These landforms have flat floors and contain material that are brighter than the surrounding surface. The surface is also rougher, suggesting it corresponds to the basement unit. They are indicated as WV (for Wide Valleys) in Figure 6a and are referred as "wide and flat valleys" in the text later. Many shallow valleys connect to these wide and flat valleys. For example, a valley at the foot of some fault
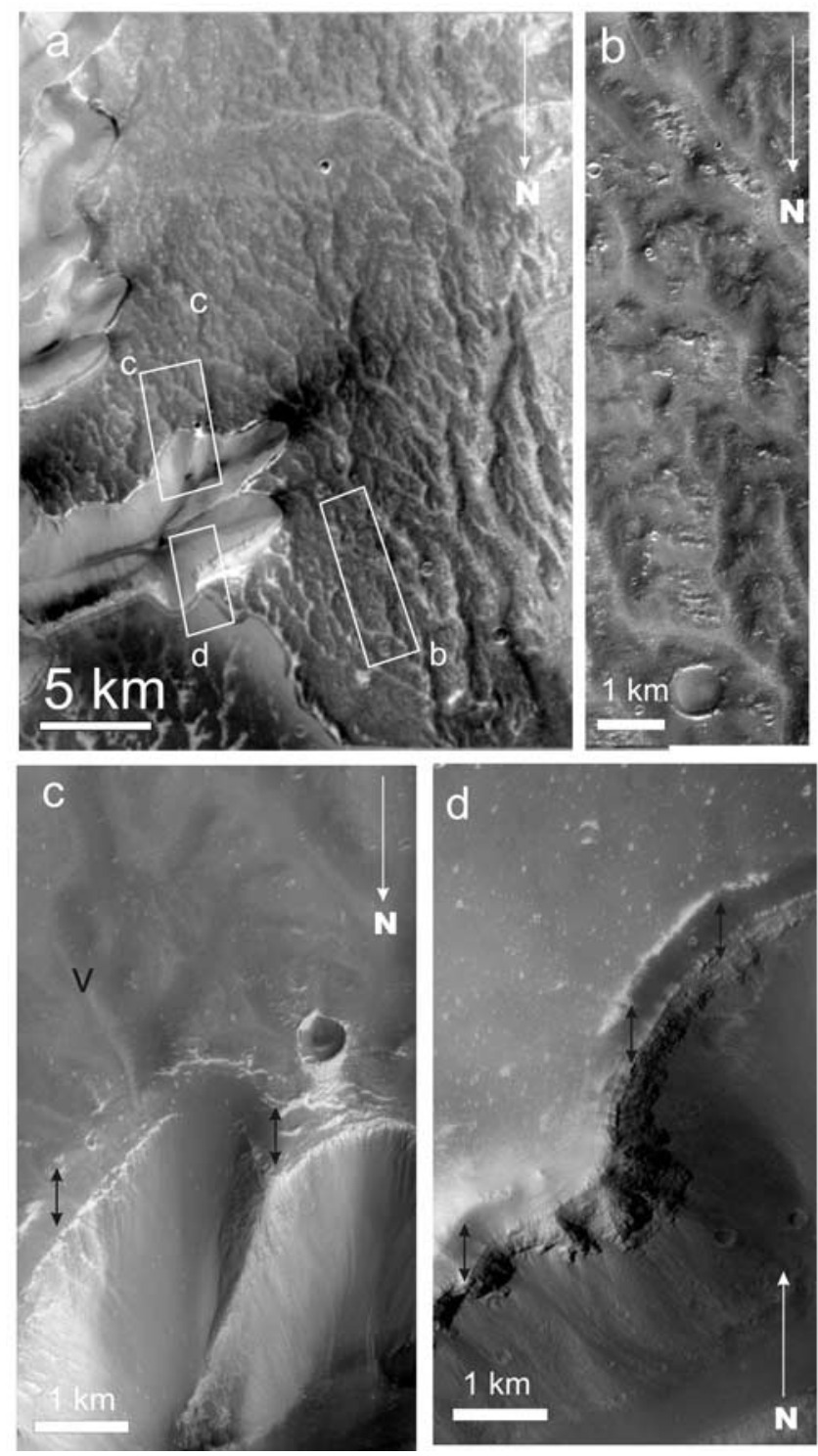

Figure 4. (a) HRSC close-up of the central region immediately south of Figure $3 \mathrm{~d}$. Valleys are dense and are cut by the EW canyons to the left. (b) Close-up of MOC image R2301115 showing an individual valley filled with bright aeolian material. Notice the degraded nature of impact craters in this image. (c and d) Close-up of MOC image S0301365 over two canyons scarp. Double black arrows indicate top and bottom boundaries of a dark, smooth unit that overlies canyon wallslopes, which are identified by their rocky outcrops. The "v" indicates a valley section that crosses the dark smooth material, but not the rocky wallslopes. 


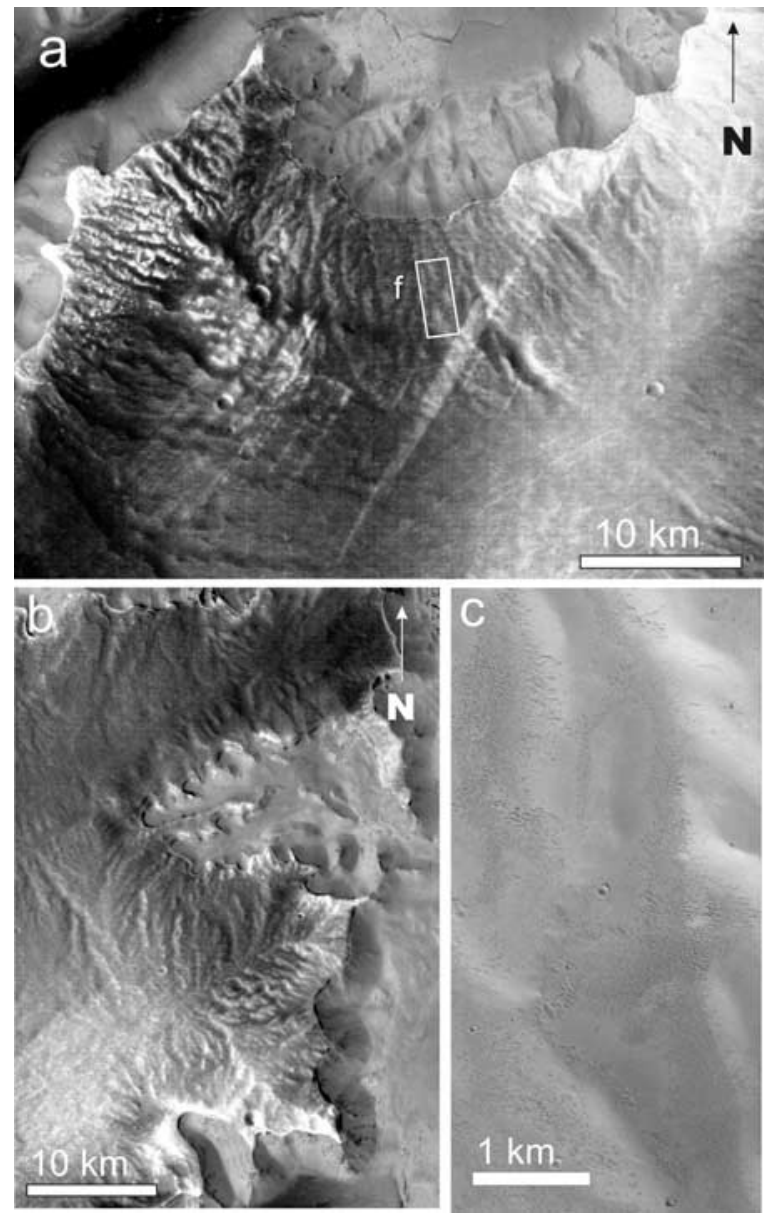

Figure 5. ( $a$ and b) HRSC close-ups of the plateau north of the central area. This image displays small valleys that are poorly ramified compared to the central area. (c) Closeup of MOC image S0702734 seen in (Figure 5a). The terrain is smooth, relatively brighter than the terrain to the south, and are covered by small aeolian ripples. The valley appears as a broad and shallow depression, which is likely the result of the blanketing by aeolian mantling.

scarps becomes a wide and flat valley and connects to the main wide and flat valley crossed by the MOC image (Figure 6c). The surface of these valleys indicate locally lineations parallel to the apparent slope (Figure 6c); these features might correspond to erosional grooves. These landforms suggest that wide and flat valleys have collected water flows from the shallow valleys, but that the erosion did not incise deeply into the underlying bedrock. We also observed that the main wide and flat valley branches at the head of the long tributary canyon that dissects the plateau (Figure 2).

\subsection{Landforms West of the Central Area Across the Long Tributary Canyon}

[17] Some patterns resembling valleys can be observed west of the long tributary canyon (Figure 7). The largest one appears to be another wide and flat valley, as seen in Figure 6, connecting to the tributary canyon head. Some other valley-like landforms appear around these wide and flat valleys, but they do not always connect together and sometimes display branching patterns. An aeolian blanket identified by sand dunes and aeolian erosion modify the patterns (Figure 7b). Small impact craters $(<1 \mathrm{~km})$ have been heavily modified because they often show poorly preserved rims. These craters and several troughs are also filled by aeolian mantling, suggesting the erosion produced material that is locally deposited in topographic lows. Thus we interpret this area as a transition from gently eroded areas where valleys are partially preserved into much more degraded area where valleys are too heavily modified to be mapped.

\subsection{Other Valleys in the Echus Chasma Region}

[18] The areas where fluvial landforms are apparent question whether fluvial landforms are more widespread in the surroundings. Some valleys are located close to the plateau edge (Figure 8) northward to the limit of Figure 2 (see Figure 1 for location). Valleys are not found everywhere on the plateau, but when they are observed they display a dense network. A topographic divide with several valley heads is visible at the crestline of a linear hillslope (Figure 8b). West of that area the valleys fade into a smooth plain. Near the transition between valleys to smooth plains, we observed some raised, sinuous landforms (Figure 8c), which resembles inverted channels (i.e., deposits of channels floors that more easily resist erosion). Notice one valley connects to the head of a canyon in Figure $8 \mathrm{~b}$. No valley incision is visible in the canyon wallslopes at the resolution of the HRSC.

[19] Valleys can also be observed on the eastern side of the Echus Chasma (Figure 9a, see Figure 1 for context), at the same latitude as the main valley systems (Figure 2). These valleys are deep and less branching than in the western part, which is likely due to a steeper slope at this location $\left(>2^{\circ}\right)$. Here valleys seem to erode into the plateau bedrock much deeper than in any other locations. Other landforms similar to valleys observed on Figure 4 are found on the southern edge of Echus canyon (Figure 9b), but they are small and display a low degree of connectivity. Around Hebes Chasma a single valley on the southern plateau connects to the head of a canyon tributary (Figure 9c) and displays sinuosity typical of fluvial landforms, but no obvious tributaries are seen. All of these valleys extend the location of observed fluvial systems to about $300 \mathrm{~km}$ in the $\mathrm{N}-\mathrm{S}$ direction and $150 \mathrm{~km}$ in the $\mathrm{E}-\mathrm{W}$ direction.

\subsection{Fluvial Landforms on the West Juventae Chasma Plateau}

[20] Juventae Chasma is located NE of the Valles Marineris area (Figure 1). This canyon is a closed depression about $4 \mathrm{~km}$ deep with a single outlet toward the north. An HRSC image from orbit 243 provides the context of this region (Figure 10). The canyon wallslopes display spur and gully morphology typical of Valles Marineris canyons with thick layering visible at the top of the scarps. The surrounding plateau of Juventae is part of Lunae Planum and consists of smooth plains.

[21] Sinuous lineations are visible on the edge of the Juventae plateau in a HRSC image (indicated as SL on Figure 11). They have raised topography with an albedo slightly higher than the plateau material and are typically 20 to $200 \mathrm{~m}$ wide with a length $>10 \mathrm{~km}$. Many of them connect 

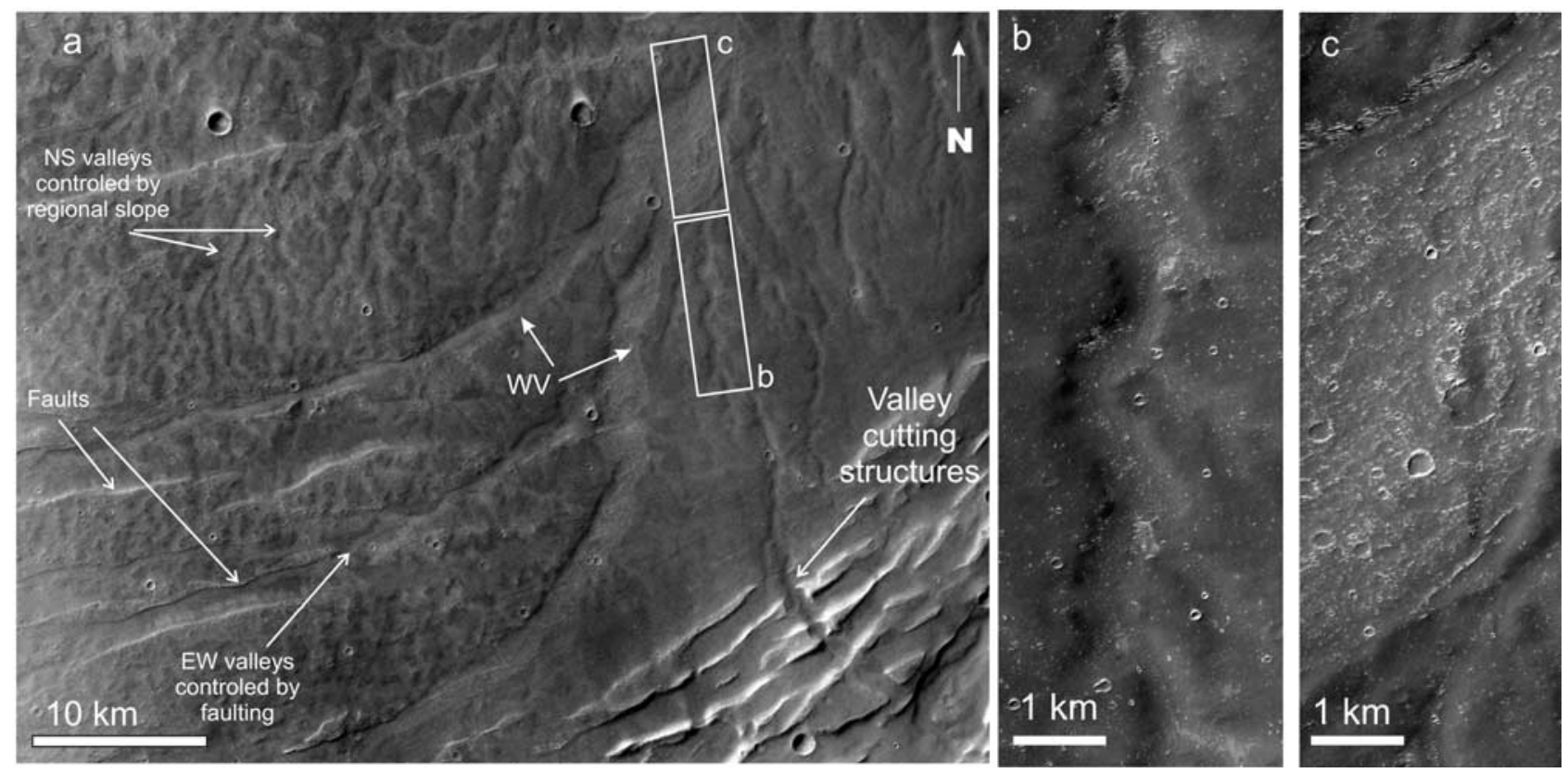

Figure 6. Close-up of HRSC image 920 southwest of the central area. The importance of faulting in this area is obvious. Valleys are sometimes cut by faults, but are controlled by the regional slope to the north. Several valleys follow the EW faults connecting to a large valley to the east. Valleys also cut into faults toward the SE. The large valleys named WV are wide and flat, and appear different from the typical shallow valleys. (b and c) Close-up of MOC image S0300138 presented in Figure 6a. Figure 6b shows a shallow valley incising into the dark smooth unit as seen in Figure 4. Figure $6 \mathrm{c}$ shows the rough floor of the wide and flat valleys (WV).

together with branching patterns. Their organization indicates more connections in the southern part than in the northern part of Figure 11a. SL fades northward as if they were modified. In Figure 11b west of Juventae Chasma the sinuous patterns are less developed and have lower connectivity. Nevertheless, when observed, sinuous lineations are also wider to the north. In several MOC images (Figures 11c and 11d) sinuous lineations are arranged in branching patterns that mimic fluvial networks. We observed that
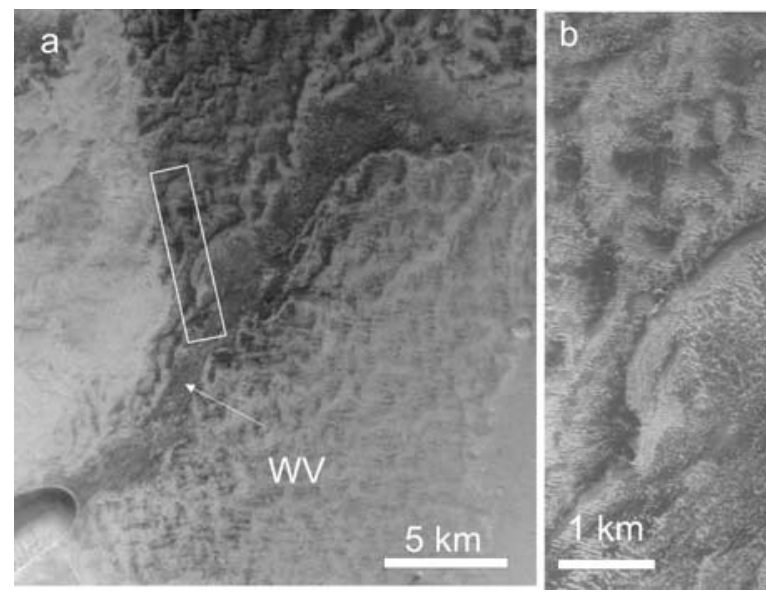

Figure 7. (a) HRSC close-up of the western part of the plateau with a wide and flat valley connecting to the canyon head and patterns that are not well organized around. (b) Close-up of MOC image R1502096 showing the WV valley at the bottom and the heavily degraded terrain. With the exception of the valley WV, no smaller valleys are visible. two small branches connecting together form a wider lineation (arrow on Figure 11c). The average widths of the SL increase northward while the total number of these features decreases. It is important to note that the sinuous lineations differ from tectonic features, such as wrinkle ridges, in the way they branch together and increase in
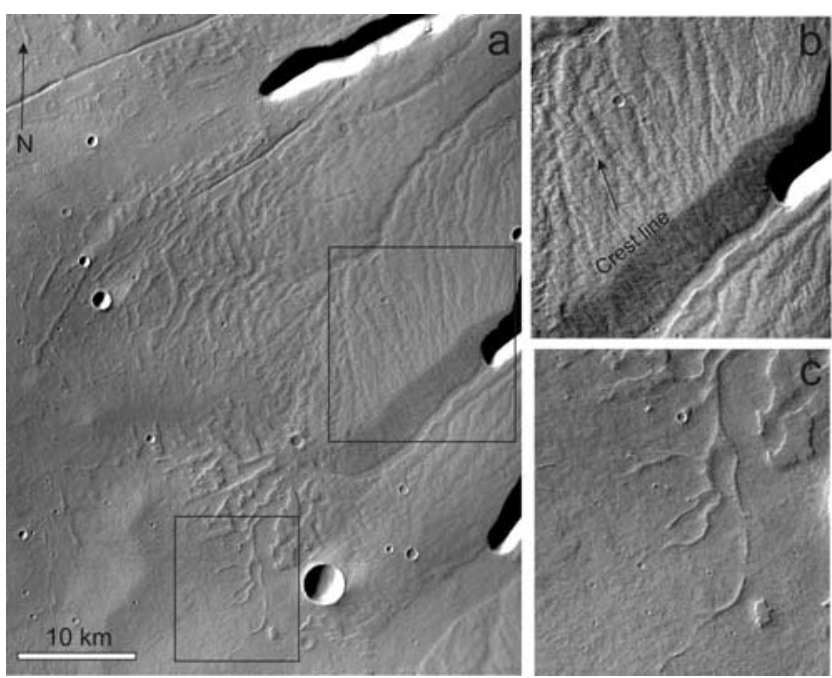

Figure 8. (a) Close-up of a HRSC image north of the Figure 2 (see Figure 1 for location). (b) The valleys heads mark the topographic divide. Figure 8c shows inverted landforms that appear to be residual material found toward the east. Erosion of the material becomes more pronounced from the east to the west. 

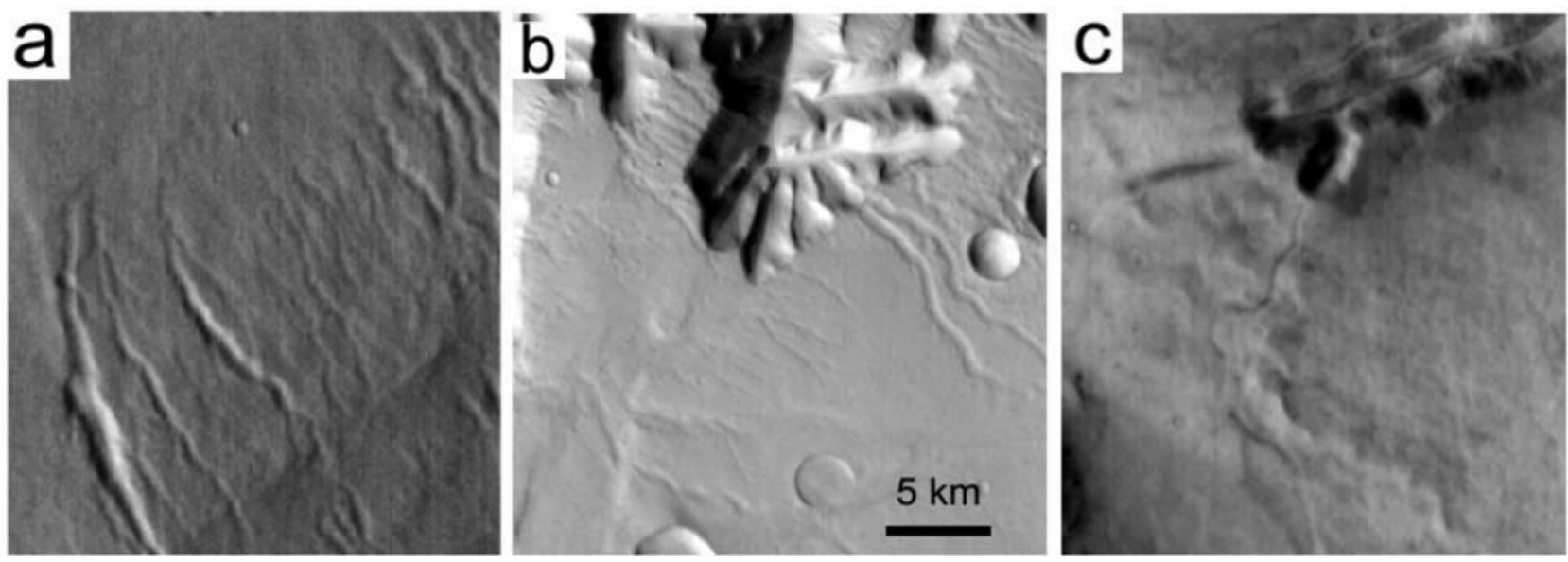

Figure 9. THEMIS images of valleys around (a) Echus Chasma, (b) East Plateau, and (c) South Plateau, a small single valley connecting to the head of a canyon tributary of Hebes Chasma. See Figure 1 for location. Scale is for the three Figures; North is to the top.

width. Assuming the sinuous lineations are due to some kind of aqueous flows, the organization of the branching patterns suggests that the topographic slope was oriented to the North. MOLA topography shows that the regional slope of $0.2^{\circ}$ dips away from the canyon rim and is therefore in agreement with the organization of the lineations. In the HRSC images, the sinuous lineations seem locally embedded into the uppermost unit of the plateau (Figure 10), as it was the same unit. This upper unit is composed of thin layered deposits [MOC \#R0903652, e.g., Lucchitta, 2005]. This uppermost unit forms mesas, suggesting this was a larger unit before erosion. The fact that sinuous lineations are embedded into these layers suggests that these layers are part of a larger deposition system (e.g., alluvial system) now strongly eroded with sinuous lineations being more resistant to erosion than surrounding material. Alternatively, sinuous lineations might come from the erosion and downward redeposition of this layered material.

[22] These observations suggest: (1) Sinuous lineations were formed by some type of aqueous flows; (2) the exhumation of this material by wind erosion dissected the plateau deposits and outlined the lineations by differential erosion. Inverted channels usually form by, either subglacial
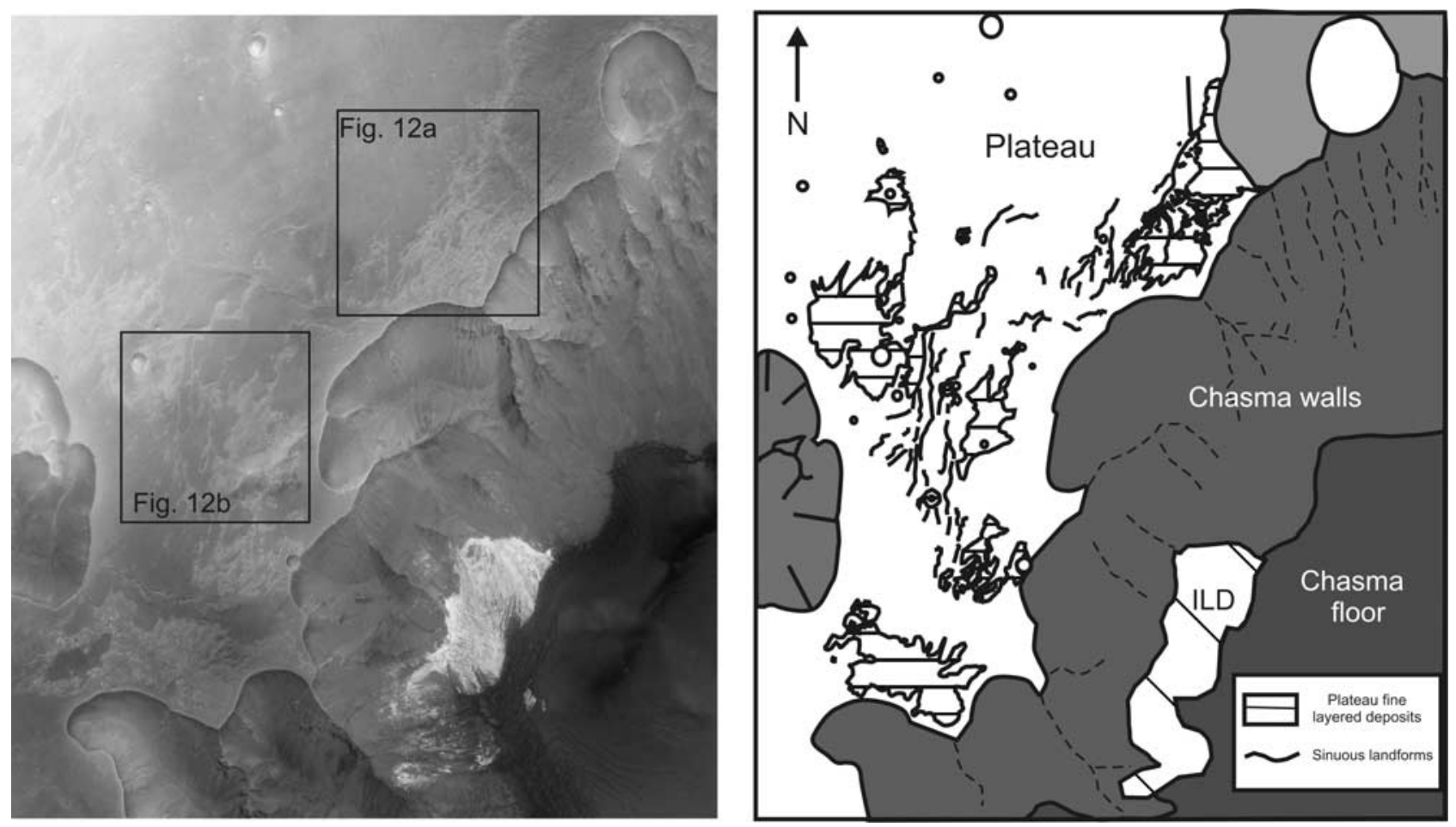

Figure 10. An HRSC image (\#243) of the plateau west of Juventae Chasma (left) with geomorphic map of the same area (right). The plateau displays landforms that are detailed on Figure 11. 

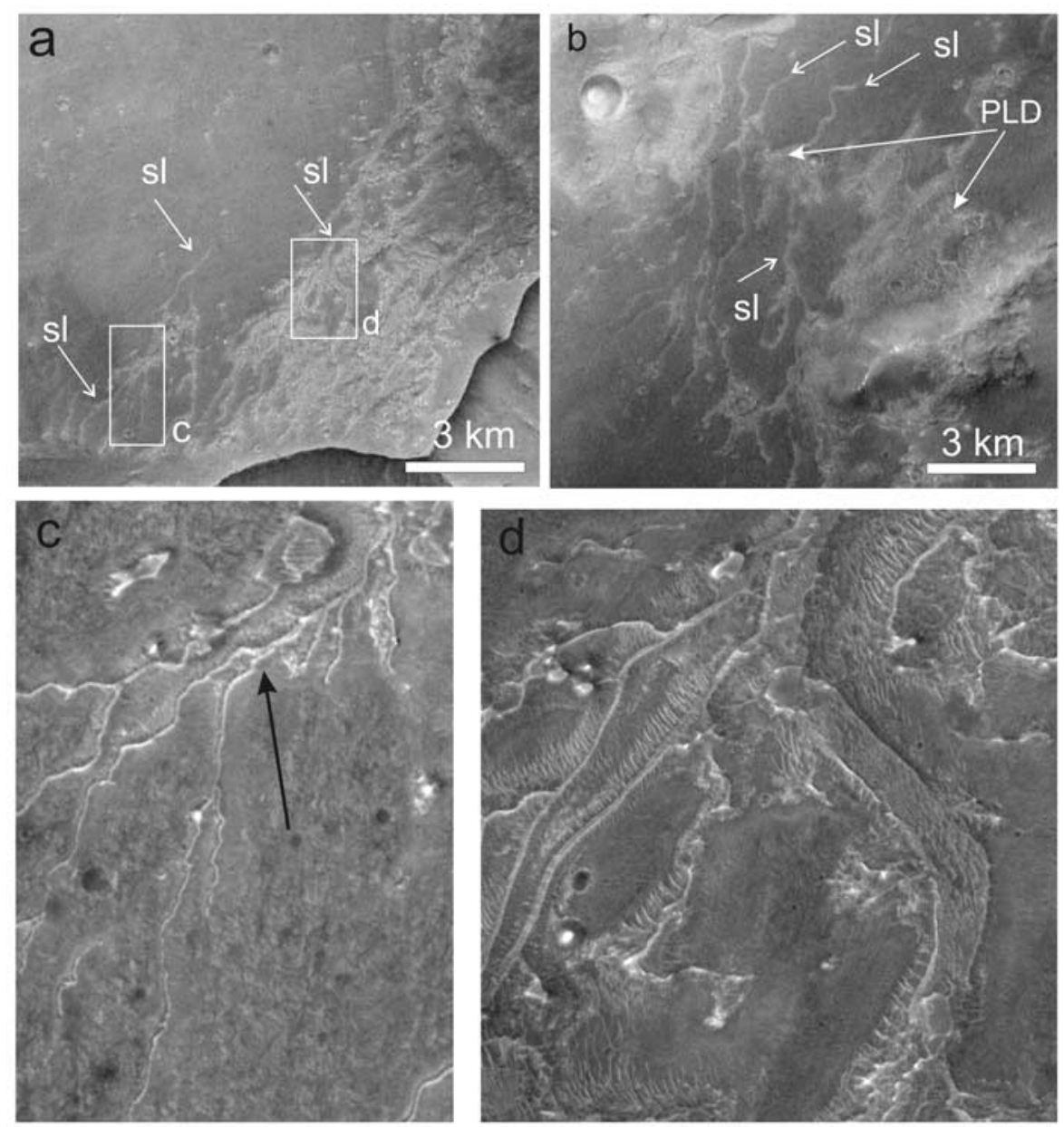

Figure 11. ( $a$ and b) Close-up of a HRSC nadir image 243. (a) Sinuous lineations (SL) are observed close to the plateau edge. (b) The sinuous lineations are discontinuous and often associated with small mesas of a plateau material (PLD). Notice that the large hill at the bottom right corner consists of preexisting topography. (c) MOC images of sinuous lineations. The arrow indicates one of the connections between sinuous lineations, which indicate a flow direction to the north. Lineations also become wider toward to the north (downslope direction).

flows (i.e., eskers) or are the result of fluvial channels inverted by differential erosion.

[23] These landforms are only partially preserved, so it is difficult to quantify any characteristics related to fluvial flows. We found other sinuous lineations within friable plateau material west of the Ganges Chasma canyon [MOC \#R1500751, e.g., Williams, 2007]. This location has fewer sinuous landforms, and the plateau layered deposits are less well preserved, but their similarity with those of Juventae Chasma suggests that the occurrence of these landforms is not restricted to the Juventae region.

\section{Thermal Properties of the Substratum}

[24] The efficiency of fluvial erosion depends strongly on lithology. An analysis of the THEMIS IR data and the HRSC images helps to characteristize the nature of the surface materials. In the Echus Chasma plateau region, valleys are accentuated by the differences in the thermal properties between valley floor (dark) and the surrounding incised material (bright) on the THEMIS nighttime images
(Figure 12). The thermally dark areas within the nighttime image are devoid of valleys, suggesting that a mantle of low thermal inertia material is present (Figure 12). This low thermal inertia material is found in regions covered by a thick dust mantle in the HRSC images (Figure 5), and is confirmed by the thermal data that shows a TES derived thermal inertia below $80 \mathrm{~J} \mathrm{~m}^{-2} \mathrm{~K}^{-1} \mathrm{~s}^{-1 / 2}$, which is consistent with mobile dust [Putzig et al., 2005]. This mantling material is likely the same that locally fills valley floors. A mantle deposit also likely exists in the south as seen by the reddish color in HRSC images. However, the presence of this pattern is not visible on the THEMIS nighttime IR, which suggests here a very thin dust deposit. Indeed, thermal infrared imagery takes the first tens of $\mathrm{cm}$ of the ground in account [Christensen et al., 2003] and are poorly influenced by a very thin layer $(<1 \mathrm{~mm})$. We therefore suggest that the southern part is blanketed by a thin veneer of dust that influences the albedo, but has little effect on the thermal properties.

[25] The locations incised by valleys in Figures 3 and 4 correspond to high nighttime temperatures indicating they 

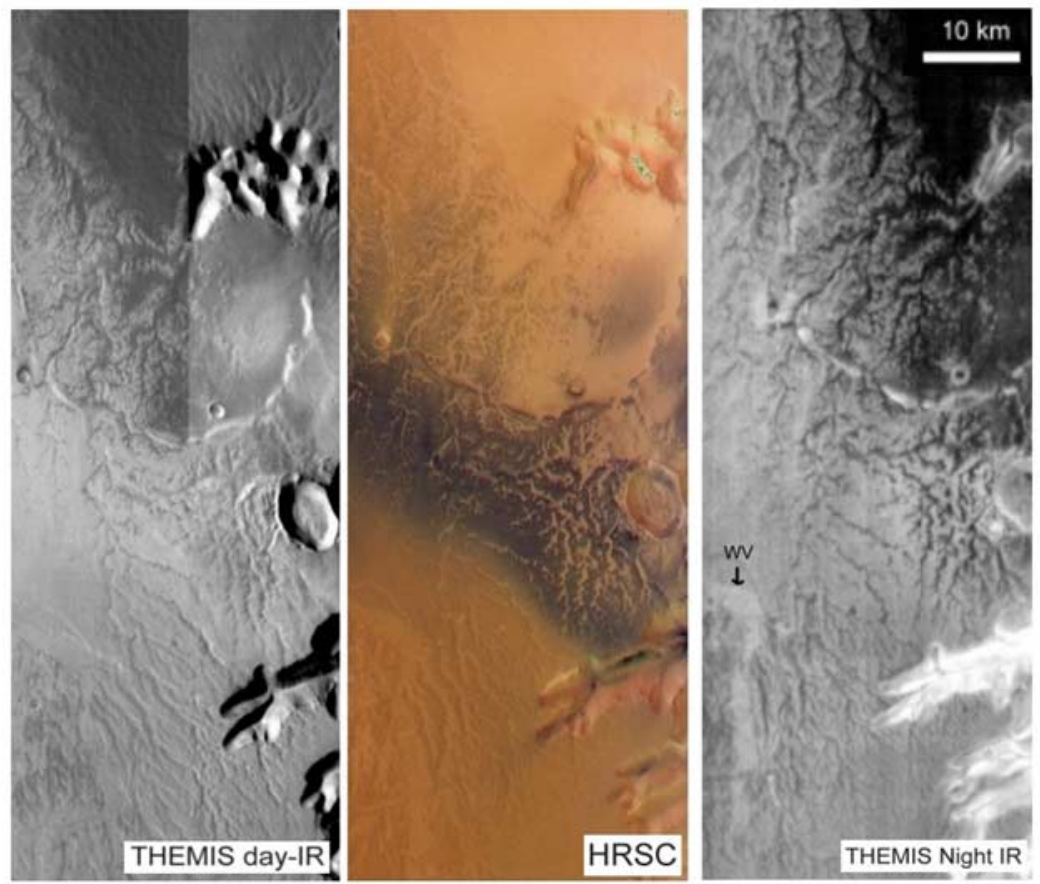

Figure 12. THEMIS daytime IR, HRSC color (uncalibrated) and THEMIS-nighttime IR of the central area. Dark areas in the nighttime image correspond to bright reddish terrains in the visible image that likely correspond to dust deposits. The reddish area to the south of HRSC image indicates likely a very thin deposit as it does not appear in the THEMIS images. Notice the higher thermal inertia of the SW WV valley of the nighttime image.

are composed of a more rocky or indurated material (Figure 12). This material, which is bright in the THEMIS IR imagery, corresponds to the dark top unit in the HRSC images that we interpret as overlying the basement. The thermal inertia of that unit is of 200 to $250 \mathrm{~J} \mathrm{~m}^{-2} \mathrm{~K}^{-1} \mathrm{~s}^{-1 / 2}$ as seen on TES data [Putzig et al., 2005]. These values are often indicative of a slightly indurated material such as ash or aeolian deposits rather than volcanic lavas or bedrock that usually have thermal inertias over $400 \mathrm{~J} \mathrm{~m}^{-2} \mathrm{~K}^{-1} \mathrm{~s}^{-1 / 2}$ [Putzig et al., 2005]. This is consistent with our geomorphic interpretations, which favors an indurated, but relatively weak unit lying over the volcanic bedrock.

[26] A higher thermal inertia material is visible to the southwest of the Figure 12 and corresponds to the main wide and flat valley referred as wide and flat valleys. The thermal inertia of the surrounding unit is not as high as that of wide and flat valleys, as shown in the MOC image of Figure 6c. The floor of these valleys corresponds to an outcrop of basement that is not mantled. Additional valleys have also a brighter tone in the THEMIS nighttime images (Figure 13), suggesting a thermal inertia higher than the surrounding.

[27] In summary, the Echus Chasma plateau area displays three main thermo-physical units, from bottom to top: (1) a rocky basement with high thermal inertia, which is visible on wide and flat valley floors incised by tributary canyons, (2) a weak dark unit that lies over the basement, which is dissected by shallow valleys, (3) a bright albedo, low thermal inertia dust mantle that blankets valley floors and whole sections of plateau to the north.
[28] In the THEMIS images of the Juventae plateau, sinuous landforms and residual plateau material are also visible due to differences in their thermal properties (Figure 14). On the nighttime images, the darker tone of SL indicates their lower induration relative to the overall plateau or wallslopes material. If wallslopes and scarp material formed by lava flows, the sinuous lineations must be composed of weaker material. They display a thermal inertia of about $200 \mathrm{~J} \mathrm{~m}^{-2} \mathrm{~K}^{-1} \mathrm{~s}^{-1 / 2}$ in TES thermal inertia [Putzig et al., 2005] similar to the values found for the Echus Chasma western plateau upper layers. Nevertheless, differences exist between the Echus Chasma plateau upper unit and the one of Juventae Chasm. Specifically, no meter scale layering is visible in the Echus plateau while it is a main property of the Juventae plateau layered unit.

\section{Morphometry of Fluvial Landforms Using HRSC Images and DEM}

[29] Quantitative analyses of the observed valley systems are possible only where the valleys are evident and wellpreserved, which is primarily in the central West Echus Chasma plateau area and immediately south and west of this location. We limit our quantitative analysis to this area based upon the HRSC DEM created by data obtained in the orbit 2204.

\subsection{Drainage Densities}

[30] The drainage density, which is defined as the ratio between the total length of valleys and the total area of the watershed, permits an evaluation of the development of the 


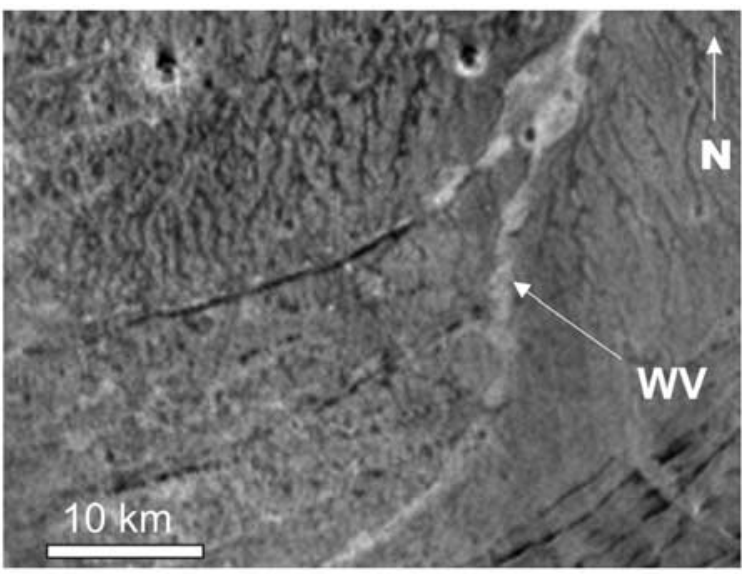

Figure 13. THEMIS nighttime IR of the area in Figure 6a. This image shows a difference in thermal inertia between the WV bottom and the surrounding material incised by shallow valleys. The brighter tone indicates higher thermal inertia.

drainage system in the basin [Knighton, 1998]. Valleys can be ordered by taking the smallest fingertip tributary as order $\mathrm{n}=1$ and then increase successive $\mathrm{n}+1$ after each intersection of two streams of order $\mathrm{n}$ [Strahler, 1952]. The precise mapping of valleys is difficult in degraded areas (Figure 2) as well as in locations where small tributaries are often discontinuous or partially buried under a dust mantle. For example, the Strahler's orders only reach 2 or 3 for valleys buried under dust (Figure 5). Bifurcation ratio and stream length ratio were not evaluated because these ratios are typically close to terrestrial values [Mangold et al., 2004], and would not necessarily give any additional information about the formation process. We discuss the drainage density using the manual mapping first, and then using the DEM.

[31] Strahler's orders are typically 4 in the central area, and locally 5 , with densities ranging from 0.6 to $1.3 \mathrm{~km}^{-1}$ for some subbasins measured at $20 \mathrm{~m} /$ pixel resolution. By comparison, the same drainage systems measured with the THEMIS images at $100 \mathrm{~m} /$ pixel have Strahler's order of 4 and densities from 0.6 to $1.0 \mathrm{~km}^{-1}$ [Mangold et al., 2004]. Thus the shallow valleys mapped from the HRSC images (Figure $2 \mathrm{~b}$ ) yield approximately the same Strahler's orders and a slightly higher drainage density than when mapped from the THEMIS images. A greater drainage density might be expected by the difference in resolution, but surface modification, observed in several images (Figures 3, 5, and 7), might affect the smallest tributaries.

[32] Drainage densities can also be extracted automatically from the HRSC DEM (Figure 15) using the hydrologic tools available in ARCVIEW GIS [Loesch, 2001]. The drainage density obtained using this method varies from 0.1 to $0.3 \mathrm{~km}^{-1}$, which is lower than the value extracted from the manual mapping [see Ansan et al., 2008 for details on automatic valleys extraction]. Parameters chosen for the extraction are adapted to avoid the detection of valleys not visible in the image that would result of DEM artifact. The fact that all valleys are not detected shows that many valleys are below the DEM resolution (Figure 15). Nevertheless, most valleys detected by this method follow the major valleys mapped manually (Figure 16), showing that the pattern of valleys relates to a true topographic expression (not just a 2D pattern), and orientation of these features follow the current topography. This second point is important in that it shows that no major topographic changes occurred after valley incision. For example, the long tributary canyon west of the central area likely cut the plateau after the Echus Chasma formation (Figure 2). All valleys bordering this canyon follow the local topography created by the canyon, suggesting the shallow valleys formed during or after the canyon formation.

\subsection{Characteristics of Valleys at the Scale of Watersheds}

[33] The automatic extraction technique enables us to identify all watersheds as defined by their topographic divides. We do not take the canyons into account in this classification as the long tributary canyon would act as a mainstream and most basins would become subbasins of this larger basin. A total of 45 basins was identified. The basins referred as $\mathrm{A}$ to $\mathrm{Q}$ are those identified when the automatic extraction technique is applied to MOLA DEM, too. Those numbered by a number after the letter (e.g., A3, Q1, etc.) are those identified uniquely using the better resolution of the HRSC DEM [see Ansan et al., 2008 for explanations]. Many of these smaller basins are associated only with one major stream that was detected automatically (e.g., Q1). A total of 17 main basins contain more than one stream by automatic detection (Figure 17).

[34] The southwest area with extensive faults appears to correspond to watersheds G, H and I only (Figure 17). Notice that faults that occur posterior to the valleys do not influence the automatic extraction, likely because they are very small. If present on the plateau prior to the valley formation, faults might have induced seepage. However, these basins are not connected to other basins northward. Thus water released at the surface of these G, H and I basins cannot, by definition, explain valleys in other watersheds (A to $\mathrm{E}$ for example). Faults as the sole source of water does not provide a general explanation for valley network formation over the whole plateau.

[35] Most valley heads, such those in basins B, C and D, are distributed along the topographic divides at the boundaries of each watershed (Figure 17). Fluvial erosion therefore occurred at the uppermost points of the plateau
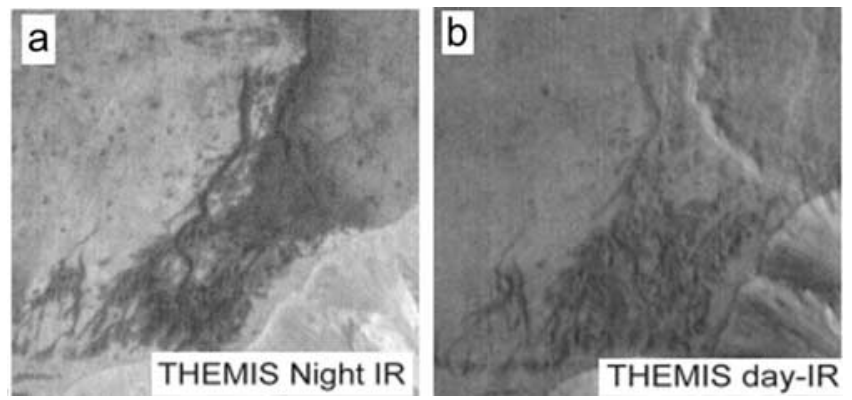

Figure 14. Night and day THEMIS IR images of the Juventae plateau showing sinuous lineations. These features appear darker than the basement indicating a finer, less indurated material than the basement. 

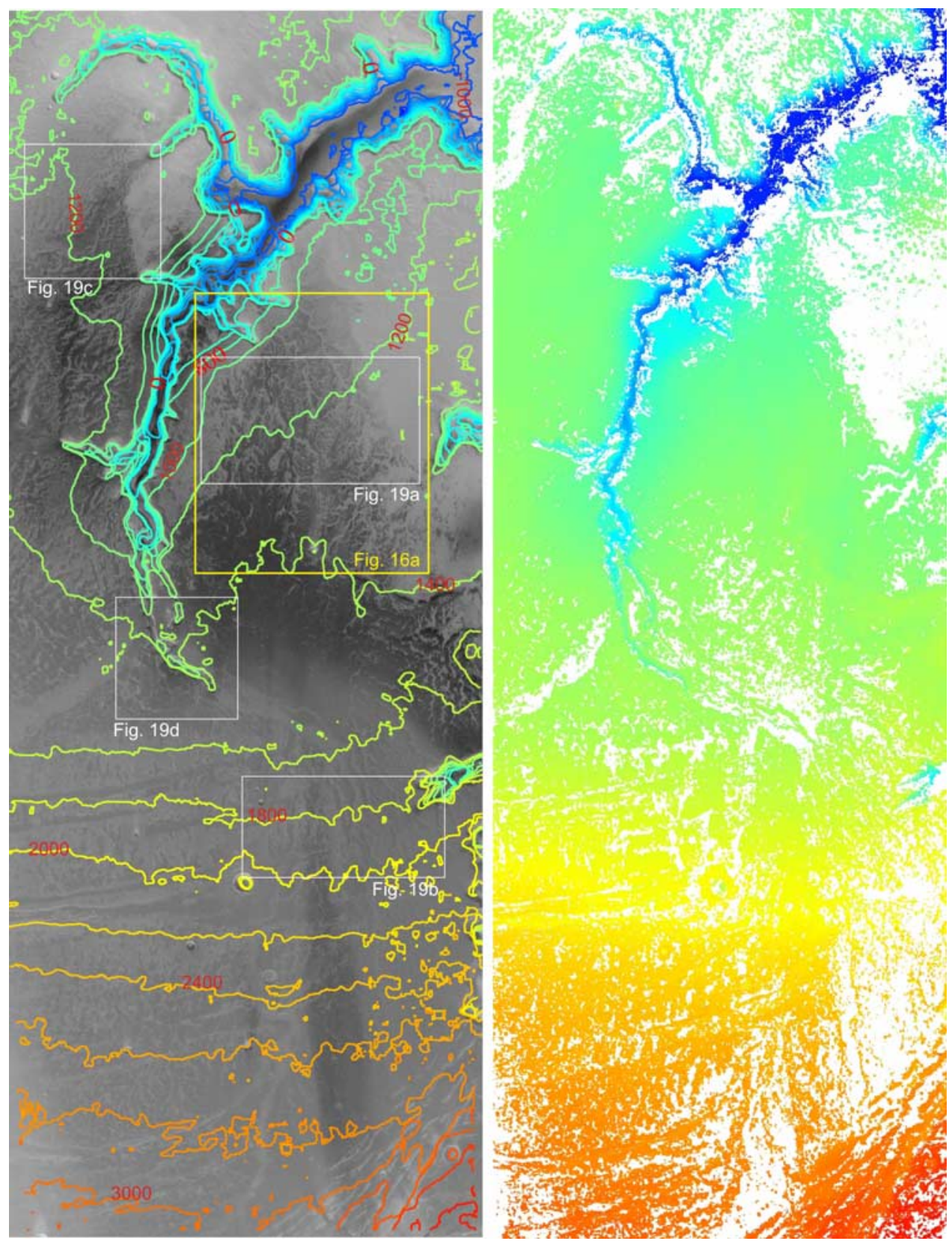

Figure 15. Topography of the West Echus plateau derived from the HRSC DEM (orbit 2204). (a) $200 \mathrm{~m}$ contours mapped over the visible image. Notice the steeper regional slope of the plateau in the south of the region. (b) Map of homologous points in the DEM with color scale as in Figure 15a. Locations with no points are in white. These areas are typically homogeneous (e.g., dust mantling) to accurately derive any topographic data. Areas devoid of points are noisy as seen on the contour lines (top right and bottom right). A dense network of points is required to use the DEM accurately. Examples in the next Figures are taken in such areas.

(Figure 18). Valley heads are not present on specific heterogeneities as expected for faults seepage or hydrothermal activity. This is a strong argument for the occurrence of precipitation and related surface runoff in the formation of these landforms.

[36] The geometry of a valley network should also be dependent on the regional slope. Phillips and Schumm [1987] demonstrated that terrestrial drainage networks formed by runoff have a dendritic pattern when they develop on slopes $<1.5^{\circ}$, and are subparallel when developed on slopes $>1.5^{\circ}$. Although the HRSC DEM has a better spatial resolution than MOLA, the regional slope is similar between both data [Mangold et al., 2004, Figure S5]. We found that valley networks are dendritic with orthogonal junction angles where the regional slope is low $\left(<1.5^{\circ}\right)$, especially in the central area (basins B, C, D) where the regional slope never exceeds $1^{\circ}$. In contrast, valley networks are subparallel, when the slopes are between $1.5^{\circ}$ and 

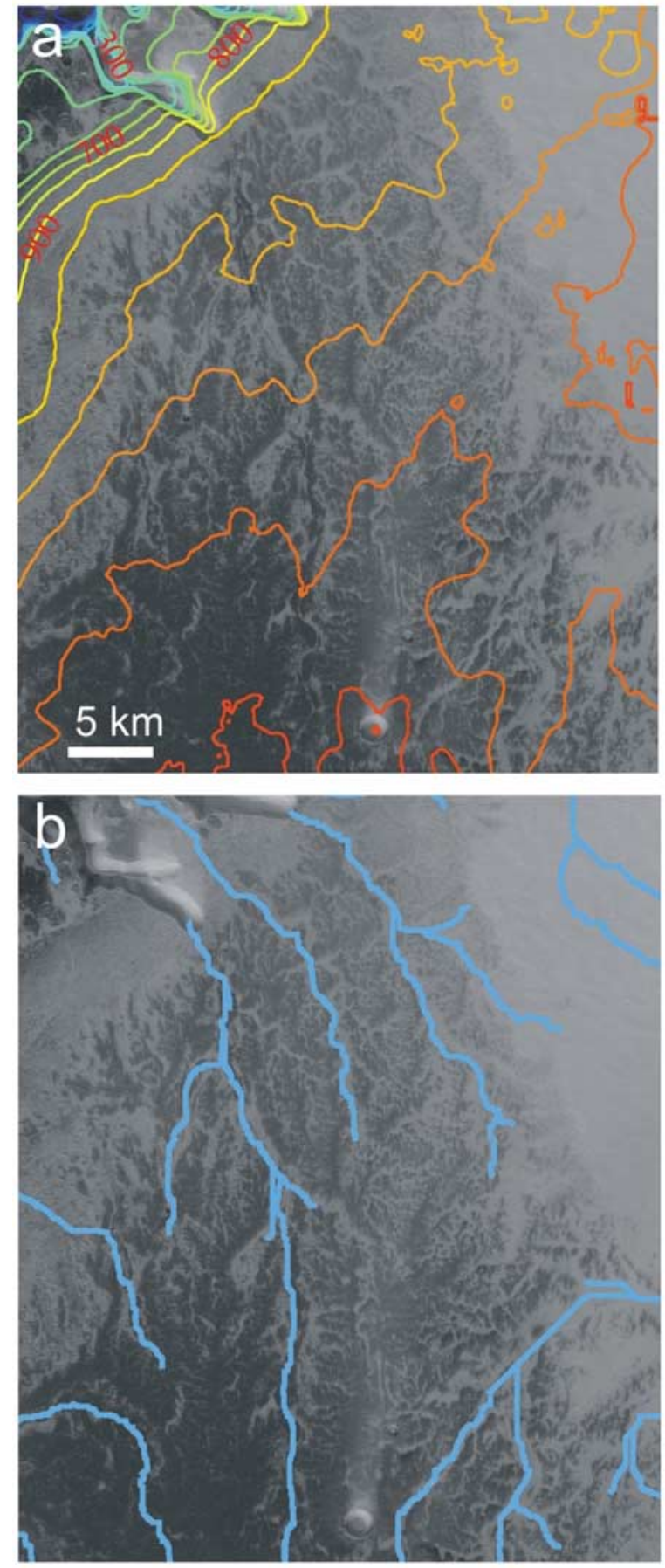

Figure 16. Detail of a region found in Figure 15b. (a) $100 \mathrm{~m}$ contours elevation and (b) valleys automatically detected in blue. The blue lines correspond to the exact location of some of the major valleys visible on the image. Many small tributaries observed in the visible image were not automatically detected from the DEM indicating that they have depths shallower than $50 \mathrm{~m}$.

$2^{\circ}$ (basin G). These observations further support the interpretation that the valley networks formed by surface runoff.

\subsection{Characteristics of Individual Valleys}

[37] Transverse profiles are obtained perpendicular to the slope in locations where the HRSC DEM grid shows a dense pattern of homologous points, therefore yielding optimum spatial accuracy. Valley depths vary from $20 \mathrm{~m}$ to about $80 \mathrm{~m}$ (Figure 19). Despite being only $20 \mathrm{~m}$ deep, valley V3 is visible on the image between V2 and V4 as a small valley close to its head. V1 and V4 correspond to the mainstreams of basins B and C. From this profile, we can see that valleys have a typical "V" shape and that they space filling to the point where there are no flat interfluves.

[38] We observed that valley V6 is a wide and flat valley (Figure 19b). The corresponding profile of this valley is up to $60 \mathrm{~m}$ deep, but with a relative flat bottom as expected from the visual observation. The floor of valley V8 is about at the same elevation $(1800 \mathrm{~m})$ as the V6 valley, suggesting it reached the same maximum depth. Potentially it could have evolved into a wide and flat valley, too. Valley V9 did not touch the basement and exhibits a V-shaped profile. On the third profile (Figure 19c), in basin O, valley V10 is wide and flat as demonstrated by its profile with a maximum depth of $80 \mathrm{~m}$. It is possible that such wide and flat valleys have completely eroded the weak uppermost unit of the plateau to display such a morphometry, suggesting that this unit remains $60-80 \mathrm{~m}$ thick in the surrounding area there.

[39] Canyons exhibit different profiles, with nearly rectangular cross-sections (Figure 19d). The canyon flank slopes are much steeper than for valleys, with $35^{\circ}$ compared to slopes between 1 and $3^{\circ}$ for $\mathrm{V}$-shaped valleys (profiles have different vertical exaggerations). This difference might be due partly to the strength difference between the basement and the weak and dark upper unit in which small valleys form, and partly to the erosion mechanism: $35^{\circ}$ corresponds to the angle of repose of dry material, whereas $3^{\circ}$ might better fit lateral erosion of valleys by riparian flows. Canyons have depths $>200 \mathrm{~m}$ at their head regions suggesting this is a minimum depth of seepage. About $100 \mathrm{~km}$ down the valley, the depth has increased to $2 \mathrm{~km}$ (Figure 15a), showing that the canyons incised more deeply downstream than at their heads, and/or, that deeper seepage also fed the canyons streams downward.

[40] The concavity of a river longitudinal profile can reflect the state of equilibrium state [e.g., Leopold et al., 1972]. Longitudinal profiles of the valley networks we studied are straight (Figure 20). Only the main valley of basin $\mathrm{B}$ presents a slight concavity as might be expected for evolved valleys. Valley $\mathrm{C}$ is straight and fits nearly the average regional slope at this location. The wide and flat valleys of basin $\mathrm{G}$ and $\mathrm{O}$ have also straight profiles. In fact, this is not surprising as valleys are restricted inside the uppermost weak unit: They should develop more concave profiles only after the basement rock was eroded. A comparison with other Martian profiles would lead to some qualitative comparison of evolution. These profiles are clearly straighter than some longitudinal profiles of Noachian age valley networks found in the southern hemisphere [Ansan et al., 2007, 2008] therefore suggesting shorter and incomplete evolution that never reached equilibrium. Nevertheless, this conclusion needs to be moderated by the fact that the lithology is an important factor in the development of valleys. The upper layer in which small valleys formed is thin: therefore, we cannot be sure that valleys would have ever reached a profile typical of equilibrium. 


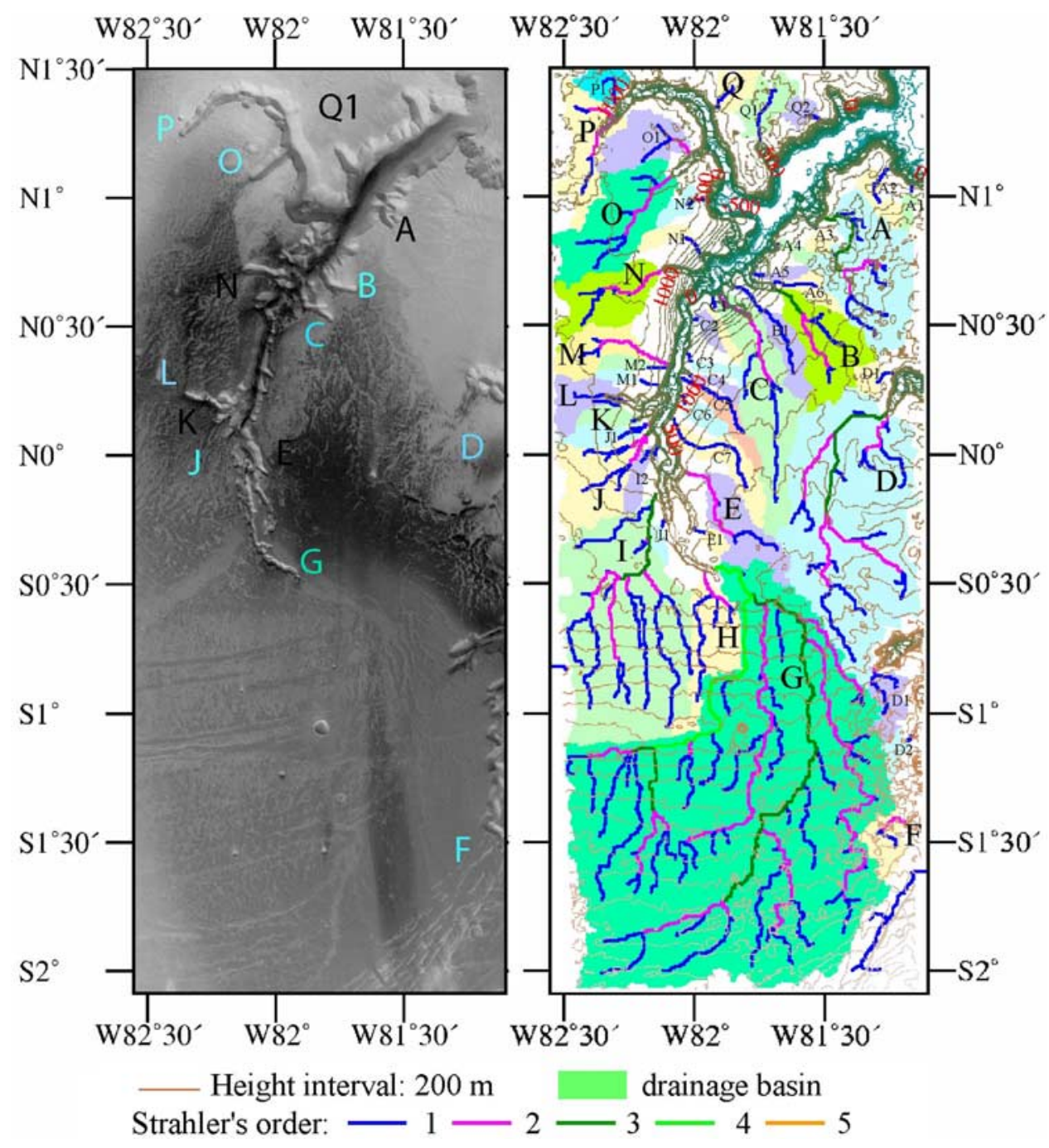

Figure 17. Right: Automatic detection of valleys using the HRSC DEM. Basins are identified with a letter, or a letter + a number. Basins are in different colors for clarity. Valleys are in blue for order 1, in pink for order 2, in dark green for order 3 and light green for order 4 . Notice the relation between most basins and the tributary canyons. Left: Image of the same area. Letters in blue correspond to those basins that connect to the head of tributary canyons as confirmed by the visual observation, and letters in black indicate those that connect in the DEM but which are not connected in the imagery data.

\subsection{Connections Between Valleys and Canyons}

[41] A more detailed look at the relationships between tributary canyons and the shallow valleys can be made through the results obtained by automatic extraction (and confirmed by the visual mapping) (Figure 18). Among the 17 basins with more than one stream detected, 14 have an outlet corresponding to the head of tributary canyons (letters on Figure 17 left). Exceptions are basins H, I, and M. Basins $\mathrm{H}$ and $\mathrm{M}$, which are small and are slightly different than valleys identified visually. Basin I is, therefore, an exception to the general correlation between canyon heads and valley outlets.

[42] The canyon head-valley outlet correlation could be misinterpreted by the automatic extraction; canyons having eroded back could have locally decrease the local topography, making a potential connection that does exist on the image. For example, D1 appears to be connected to the EW oriented small canyons of Figure 4, but this connection might be due to the later crosscutting of the canyon. We did not include basin D1 into the potential connections for this reason. However, 9 of the 14 connections (blue letter on Figure 17, left) were found to have valleys that clearly connect to the canyon heads as in Figures 2, 3, 5, and 7, confirming that this correlation is common. Of these 9 connections, 5 valleys on the plateau are wide and flat (for basins $\mathrm{G}$ to $\mathrm{O}$ ) compared to 3 shallow valleys (B to $\mathrm{D}$ ), while the last one, F, is ambiguous. Notice also that basins with wide and flat valleys (especially $G$ and $P$ ) connect to the longest narrow canyons, whereas basins $\mathrm{B}$ and $\mathrm{C}$, with shallow valleys, connect to small canyons.

\subsection{Volumes of Erosion}

[43] Estimates of the volumes of material eroded by the fluvial flows can provide information regarding the duration of valley networks formation. Estimates of the thickness of eroded material is not an easy task for the small valleys. It 


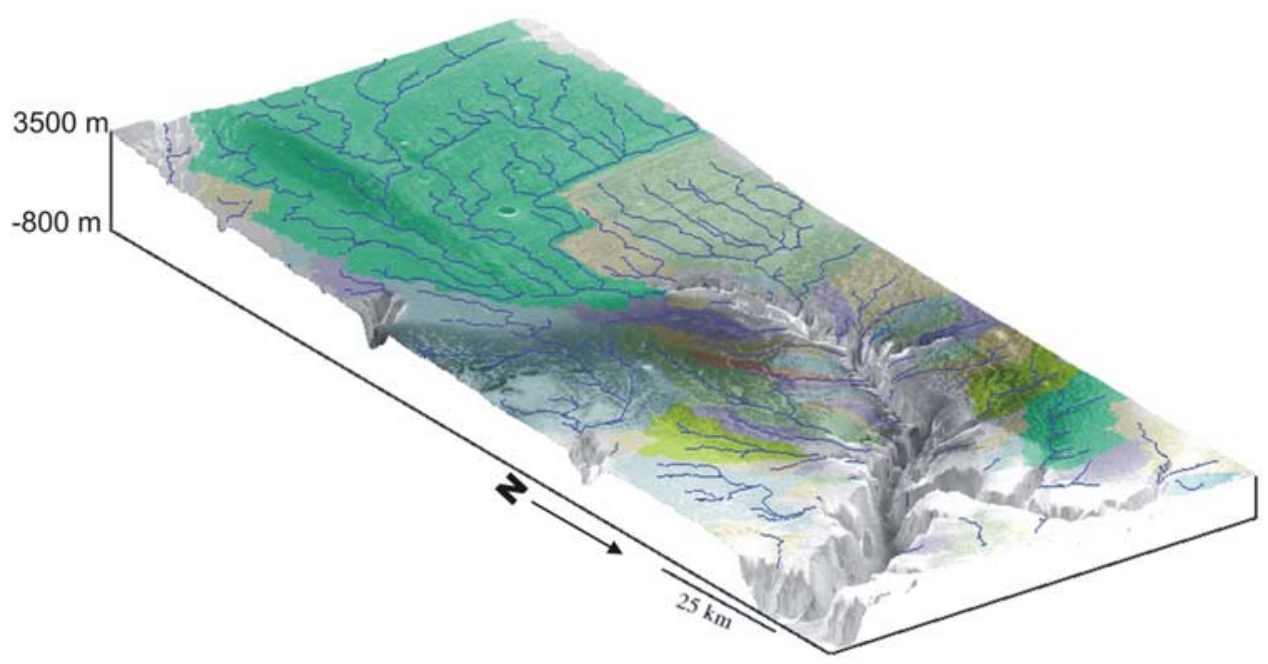

Figure 18. 3D diagram of the West Echus plateau based on the HRSC DEM automatic detection of basins and valleys. A majority of the valleys found on the image follow the same paths as those derived from automatic extraction technique. The diagram shows how valleys follow the topography created by the canyons (to the center and north) and by faults (to the south).

assumes knowledge of the original surface elevation prior to erosion, which is something not found on the plateau because the transverse profiles do not show the residual paleosurface. However, two pieces of evidence suggest the original thickness was limited to between $\approx 100 \mathrm{~m}$ and $150 \mathrm{~m}$. First, we can estimate the apparent thickness from the MOC image in Figures $4 \mathrm{c}$ and $4 \mathrm{~d}$, and from the topographic data. The MOLA DEM is not very well constrained at this location and the HRSC DEM displays too few points for a rigorous interpolation. Nevertheless, both data give the total elevation difference of $900 \mathrm{~m}$ from the rim to the canyon floor. Assuming the slope is constant the angle of repose of material is not very different whatever the material - the weak dark tone unit, indicated by arrows on Figure 4, corresponds to $1 / 8$ of the apparent length between the rim and the canyon floor, therefore corresponding to a thickness of about $110 \mathrm{~m}$. Here, valleys are relatively small, below the HRSC DEM resolution, thus limiting their incision to less than about $50 \mathrm{~m}$. Because this location was subject to relatively shallow incision only, the extrapolated layer thickness of $110 \mathrm{~m}$ is likely not far from its original value. The unit might also have been partially eroded by wind subsequently; however, this would also have eroded the observed valleys. An original thickness of several hundreds of meters thick could not explain why valleys transverse profiles are limited to less than $100 \mathrm{~m}$. Thus we assume an approximate thickness of the range of $150 \mathrm{~m}$ for the initial dark unit at the top of the plateau.

[44] We assume the eroded volume to be about half of this layer on average. Indeed, this material has been strongly eroded in some locations (as for the wide and flat valleys) and more slightly eroded in other locations. Assuming $75 \mathrm{~m}$ of average incision, based on locations with the deepest incision, we arrive at a maximum total volume excavated of $\approx 750 \mathrm{~km}^{3}$ for a $10,500 \mathrm{~km}^{2}$ area shown in Figure 15. A problem is that the areas of basin $\mathrm{G}$, and others to the west are limited to the south and west by the image coverage.
The basins might be larger, thus limiting our data in term of the total eroded volume. Volumes of the sapping canyons are easier to estimate since the canyon boundary is visible. We find an area for the canyons shown in Figure 15 to be $\approx 900 \mathrm{~km}^{3}$. This value is of the same range of magnitude as the material eroded on the plateau, taking in account the strong approximations on the latter.

\section{Summary of Geomorphic Characteristics}

[45] These observations and measurements lead to some preliminary conclusions.

[46] 1. The HRSC images confirm the identification of the dendritic valleys on the Echus Chasma plateau and allow us to identify new valleys within the broader area.

[47] 2. Shallow valleys show dendritic and sinuous patterns. Well developed braided patterns are absent, and we observe no inner channels due to an aeolian material that fills valleys in some areas.

[48] 3. The erosion of shallow valleys was limited to a dark unit that lies over the plateau basement over a thickness of the range of $\approx 100 \mathrm{~m}$; thermal data suggests this unit is less indurated or finer grained than the underlying unit.

[49] 4. Shallow valleys follow the current topography and typically have a few tens of meters depth. They have a V-shape cross-section and a straight longitudinal profile suggesting sustained surface erosion but limited long term evolution.

[50] 5. Wide valley-like landforms (WV) with flat floors are interpreted as having formed by fluvial flows over the basement rock after the valleys eroded the weak dark overlying;

[51] 6. Several small valleys, and wide and flat valleys connect to the heads of canyon tributaries to the Echus Chasma;

[52] 7. Sinuous lineations observed north of the Echus plateau and on the Juventae plateau likely correspond to 


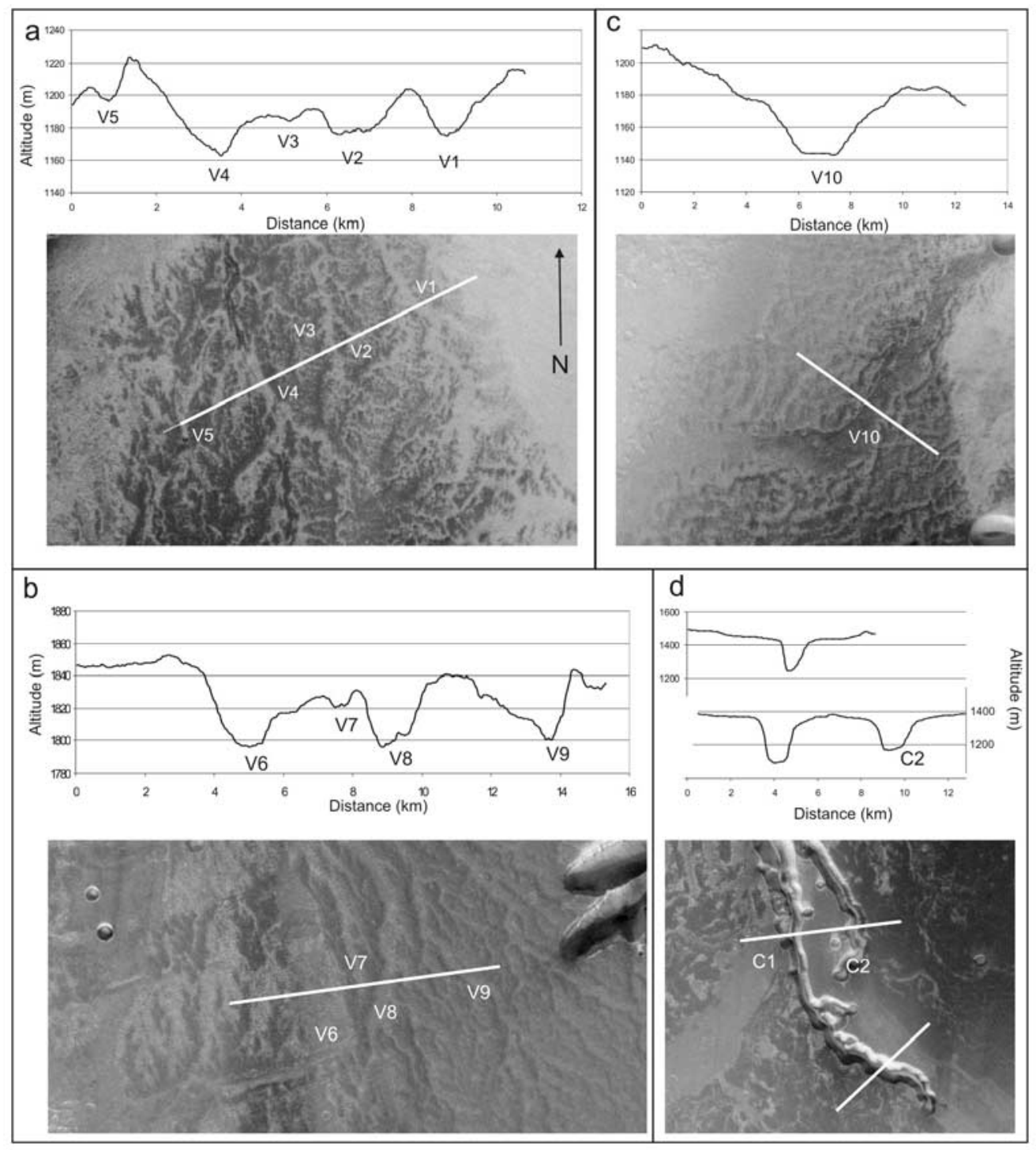

Figure 19. Topographic cross-sections from the HRSC DEM. (a) Main valleys are clearly visible on the topography with depths up to $80 \mathrm{~m}$. (b) Shallow valleys with similar depths with the exception of V6, which is a WV valley type. (c) V10 is a WV valley that is wide and flat compared to the usual shallow valleys. (d) Canyons are a minimum of $200 \mathrm{~m}$ deep close to their heads.

relief inversion due to differential erosion of this weak plateau material.

\section{Interpretation of the Formation of the Principal Landforms}

\subsection{Formation of the Sinuous Landforms}

[53] Positive relief features, such as the branching patterns and sinuous landforms of the Juventae plateau (Figure 11) and the one north of the Echus Chasma plateau (Figure 8), are commonly known as inverted landforms, which are created primarily by differential erosion, (i.e., difference in erosion rate due to differential strength of the material, [e.g., Pain and Ollier, 1995]. Inverted channels are usually able to form by two types of processes (1) subglacial flows that produced eskers and (2) fluvial channels inverted by differential erosion.
[54] Basal melting of glaciers forms channels in which sediments are deposited beneath the glacial cap. After removal of the glacier by melting or ablation, these sediments remain at the surface and form eskers. The positive topography is therefore a consequence of the formation of the channel within and below ice. Eskers were proposed to be present on Mars in different regions such as Argyre Planitia [Kargel and Strom, 1992] and close to the southern cap [Milkovich et al., 2002], as the result of ancient glacial processes close to the southern polar cap. On Earth, eskers are observed in arctic regions, such northern Canada, where they form chaotic patterns of lineations resulting from the last glacial period [e.g., Bennett and Glasser, 1996]. Assuming the sinuous lineations to be eskers, the plateau material could correspond to tills, i.e., glacial sediments deposited during glacier melting. However, other glacial landforms such as scour marks, moraines, and drumlins, are 


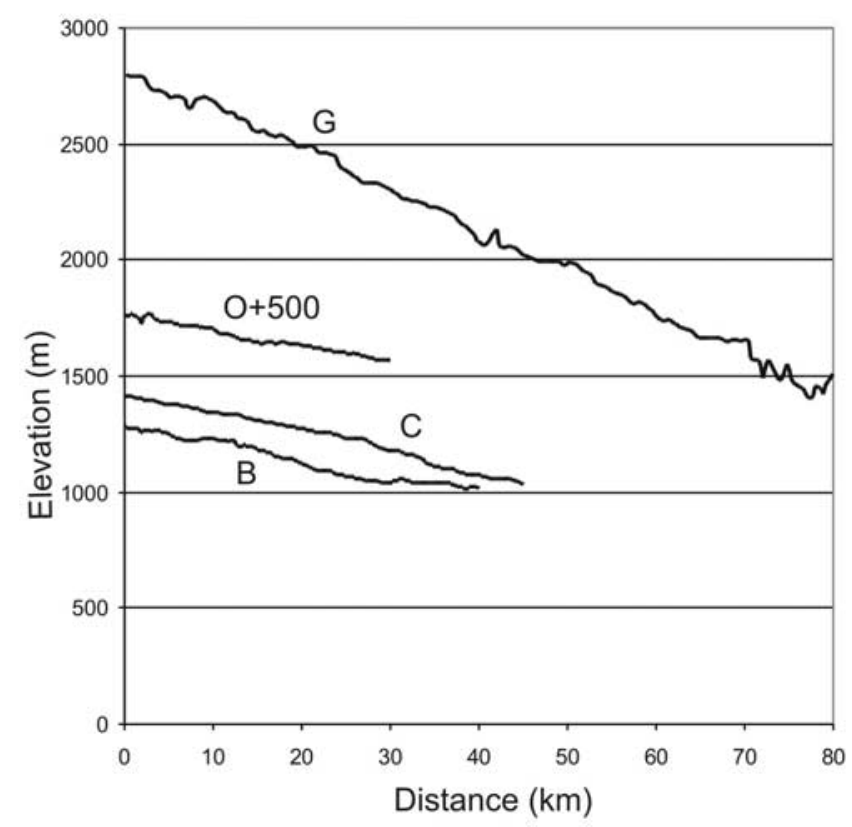

Figure 20. Longitudinal profiles along the main tributaries of basins G, O, B, and C. The value +500 indicates a shift of absolute values for clarity. Average slopes are of $0.6^{\circ}$ to $1^{\circ}$. Profiles are straight in general.

not observed on the Juventae or the Echus plateau. A second problem for this hypothesis is that the morphology of eskers is different that from the sinuous landforms observed. Eskers have an anastomosing pattern (i.e., channels that connect and then disconnect without apparent hierarchy [e.g., Bennett and Glasser, 1996]), and usually do not increase in size when they connect to another channel. These characteristics are different from those of the sinuous lineations observed on the Juventae plateau, which show a hierarchy in size and in the number of connections. In the northern Echus Chasma plateau, inverted landforms are directly found close to a valley system that does not exhibit the characteristics of a glacial outwash plain with braided channel systems (Figure 8).

[55] Fluvial flows deposit into channel particles that are frequently cemented by late fluid circulation. The formation of inverted channels occurs when fluvial erosion ceases and subsequent aeolian processes strip the surrounding finer grained material away. One terrestrial example is shown on a Landsat image of the Algerian Sahara (Figure 21a), which shows the presence of many inverted channels that are about the same size and scale as sinuous features of the Juventae and the Echus plateau. Inverted channels on Mars were observed on MOC images by Malin and Edgett [2003] in the delta-like fan in the NW Holden crater and in the Aeolis and Meridiani regions [Williams and Edgett, 2005; Williams, 2007; Pain et al., 2008]. Some of these inverted channels are not connected to obvious fluvial valleys or channels, as it would be the case in the Juventae example.

[56] In summary, sinuous lineations are likely inverted channels as supported by the spatial organization of lineations and by their orientation in the direction of slope. Aeolian erosion was a major process in modifying the landforms observed on the uppermost part of the plateau and dissecting the weak upper plateau deposits. As shallow valleys were limited to the uppermost weak unit, the geographic distribution of these landforms is dependent on the preservation state of this plateau material.

\subsection{Formation of Shallow Valleys}

[57] Several authors have proposed that valley heads on Mars may have been triggered by springs from hydrothermal flows in regions with impact, volcanism, or tectonic activity [e.g., Brakenridge et al., 1985; Gulick and Baker, 1989; Dohm and Tanaka, 1999]. At the south of the Echus Chasma plateau region, E-W trending faults show formation possibly contemporaneous to the valleys, suggesting they may have played a role in the origin of valley networks. The basins G, H and I, where faults are observed, are limited to the southwestern part of the region. Even if faults would have contributed to the seepage of water in these basins, they would not have contributed to water found at the surface of other watersheds, especially in the dendritic patterns of the central region where no faulting is observed.

[58] Release of subsurface groundwater by sapping and seepage has also been proposed to explain several small valleys, despite the fact that sapping requires substantial recharge from the surface [e.g., Grant, 2000; Craddock and Howard, 2002]. However, shallow valleys do not exhibit theater-heads and have increasing widths, contrary to typical sapping systems. The fact that valley heads are found at the summit of hills (Figure 8) and along the topographic divides of the terrains (Figure 17) also argues for precipitationdriven flows and against the role of groundwater as a primary erosion agent.

[59] The geometry of valleys favors overland flow, which can result from different processes involving either rainfall, snowmelt or glacial melting. Glaciers are predicted in equatorial regions as a consequence of periods of high obliquity [Forget et al., 2006]. Putative relics of glaciers are observed west of the large volcanoes of the Tharsis bulge such as Arsia Mons [Williams, 1978; Head and Marchant, 2003]. However, no glacial landforms have been observed on the Echus Chasma plateau. The dendritic pattern is also inconsistent with meltwater flows from glacial melting because these types of flows would not have valley heads at the topographic divides but at the past glacier front. From a morphological viewpoint, runoff due to snowmelting is impossible to distinguish from runoff due to rainfall; both processes can explain the observations.

[60] Drainage densities on the Echus plateau are below usual values on Earth, but terrestrial systems are often mapped at high resolution. Mapping terrestrial drainage basins at lower resolution shows a drainage density closer to Martian systems [Carr and Chuang, 1997]. In addition, this comparison should be done with ancient valley systems that are no longer active and are partially eroded or buried, such as in desert regions, rather than with active systems. For example, the valleys visible in a Landsat image of a region in Mauritania (Figure 21b) are visible due to their difference in albedo caused by sand deposits, similar to those on the Echus plateau. These valleys formed during wet periods of the last glaciation [e.g., Mikovsky et al., 1991]. The drainage density of the visible network in this area is $0.4 \mathrm{~km}^{-1}$, as mapped at $28 \mathrm{~m} /$ pixel resolution 

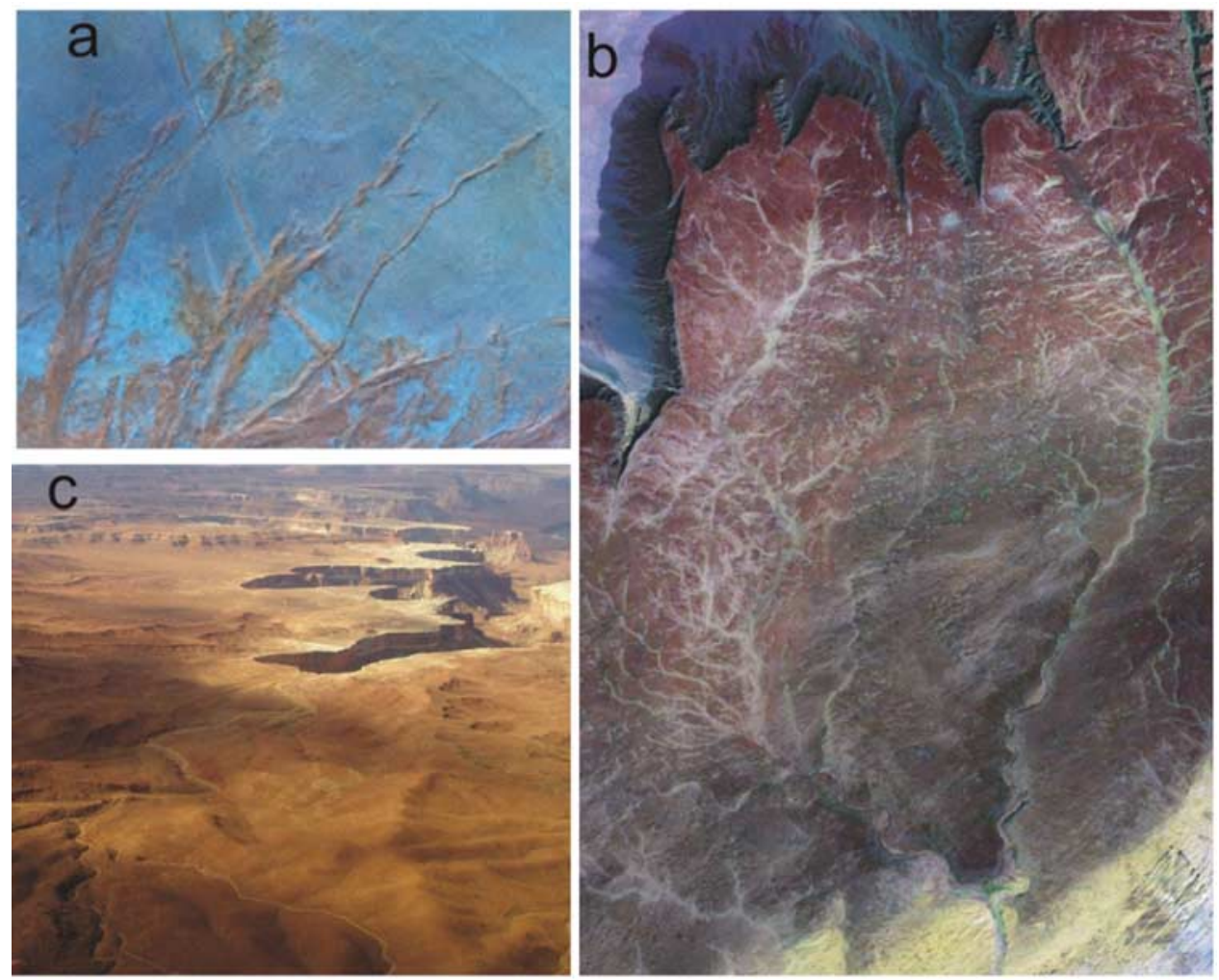

Figure 21. (a) Close-up of Landsat image on a lacustrine plain in Algeria that contains inverted channels from former rivers. (b) Landsat image of Mauritania displaying valley networks on a plateau with sand filling valley floors that accentuate their pattern. (c) Photograph of the Green River at Canyonlands showing deep canyons typical of sapping processes (image by the authors). Notice the small valley that connects to the canyon head.

comparable to the HRSC images. This shows that similar values can be found on Mars and Earth for valleys chosen in a similar context and scale.

\subsection{Formation of Tributary Canyons}

[61] Tributary canyons of Echus Chasma have theatershaped heads, vertical cross-section and a 2D organization suggesting that sapping processes might have been involved. As described by Laity [1988], requirements for sapping include (1) a permeable aquifer (2) a rechargeable groundwater system (3) a free face at which subsurface water can emerge (4) some form of structural or lithologic inhomogeneity, such as jointing in sandstone or dikes in volcanic material, that locally increases the hydraulic conductivity and along which valleys grow and (5) a means of transporting material released from the scarp face. To this, we can add the requirement of (6) a regional dip of layers of 1 to $4^{\circ}$ [Laity, 1988]. We can explore each point to see how our data fit with these parameters.

[62] Points (1) and (3): The permeable aquifer and the free face are provided by the thick lava flow series that were cut by the Chasmata wallslopes. The presence of a free face is consistent with the fact that tributary canyons must have formed after the opening of the main canyon (Echus Chasma). Permeability must be large for the water to infiltrate. Sapping canyons observed on the Colorado Plateau are due to the high permeability of the Navajo sandstones [Laity and Malin, 1985]. Another type of material that favors sapping is basaltic flows, as observed in Hawaii [Stearns, 1966; Kochel, 1988; Lamb and Dietrich, 2004]. The plateau of Valles Marineris consists of kilometers thick series of volcanic material that might be permeable, if composed only of lava flows [e.g., Lucchitta et al., 1992]. This point has been mentioned previously [Laity and Malin, 1985; Howard, 1988; Lucchitta et al., 1992] as a possible analogy between the Valles Marineris plateau and the Colorado Plateau.

[63] Point (2) states that sapping cannot form without the recharge of the aquifer. Indeed, sapping channels are unlikely to have resulted from one-time dewatering of upland groundwater reservoirs, unless the contributing upland area was much larger when the valleys formed [Howard, 1988]. The erosion of a canyon by water might require a water: sediment ratio of nearly $10^{5}$ [Howard, 1988], which is lot of water to explain sapping canyons formation in one episode of progressive discharge of groundwater. In the studied case, it would imply a basin of very large extent to explain the canyons observed. Alternatively, the episode of recharge could have been recorded in the landscape by the formation of small valleys at the surface.

[64] Point (4) comes from the observation that the widespread jointing of the Colorado sandstones creates an increased permeability in the direction of the joints [Laity and Malin, 1985]. On the Echus Chasma plateau, a few canyons follow a structural control, especially in the southern part (Figure 4a) where they occur in a $\mathrm{E}-\mathrm{W}$ direction 


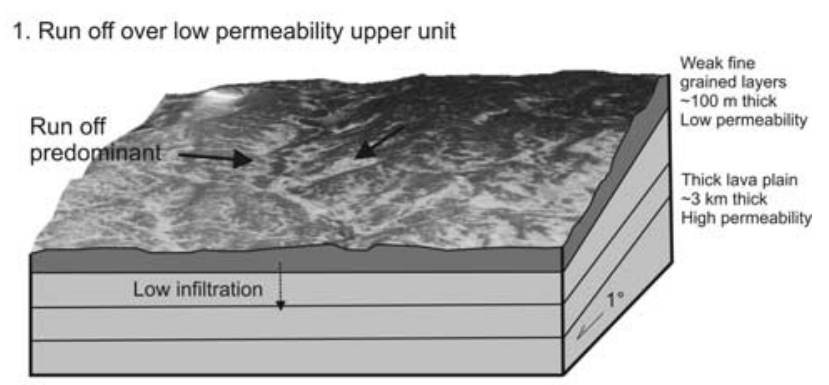

2. Erosion reaches basement on main valley floors

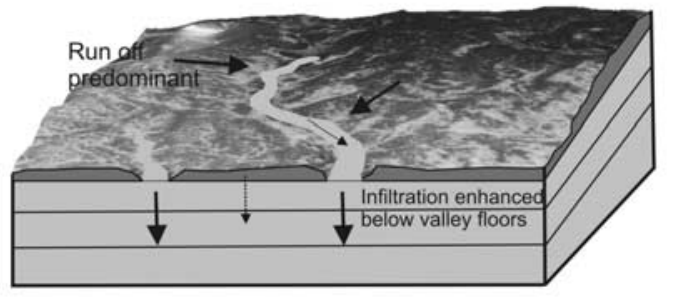

3. Erosion of canyons into the main valleys floor

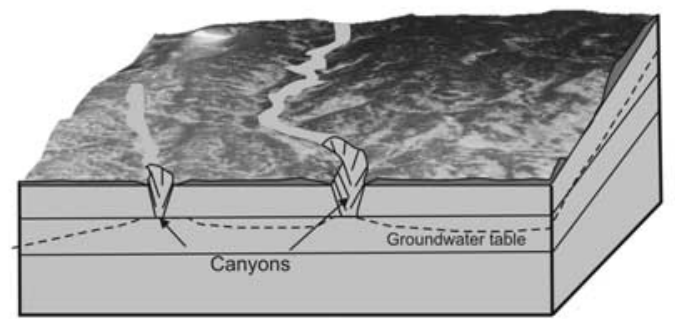

Figure 22. Proposed scenario for the coeval formation of shallow valleys and tributary canyons. The scenario is based on the observation of a dark tone unit at the top of the lithologic sequence that lies over the basement composed of volcanic lavas. See text for explanation.

similar to direction of the main faults in the southwestern area. However, most canyons in the Echus Chasma region do not follow structural patterns but seem to follow the overland system.

[65] Point (5) states that sapping can occur only if some flows are capable of transporting away eroded materials from the head of the canyons. This requires the presence of fluvial flows in the bottom of sapping canyons. Unfortunately, most canyons are buried by the lava flows that filled the Echus Chasma bottom and by eolian deposits trapped in some of the narrow and deep canyons. This prevents any investigation of fluvial landforms at the canyon bottom. Finally, point (6) is consistent with the presence of sapping in our area. The plateau dips toward north at a regional scale with dips from 1 to $2^{\circ}$.

[66] Most conditions for the formation of sapping canyons as defined by Laity and Malin [1985] seem to be fulfilled. Nevertheless, canyons are sometimes sinuous and the outlets of small valleys are frequently connected to the heads of tributary canyons (Figures 3a, 3d, 5, and 7). On Earth, valleys on plateaus frequently join the heads of sapping canyons as well (Figure 21c). This observation is not fully understood. Sapping due to groundwater would result in the same paths as overland flows if both flows were controlled by the same heterogeneities in the topography, such as faults [Laity and Malin, 1985]. Some alternative studies suggest that overland flows incise canyons through waterfalls on the cliff [Irwin et al., 2006; Lamb et al., 2006, 2007]. This might explain the sinuous shape of some canyons and the connection between valley outlet and canyon head as well. The formation of tributary canyons by overland flow, or a contribution to it, is therefore possible. However, overland flow cannot explain tributary canyons where no valley connects the canyon head (e.g., Figure 4a), showing that overland flow only cannot explain the overall erosional system. Sapping should have played a role, at least in the late evolution of canyons formation.

\section{Discussion}

\subsection{Toward a Scenario of Formation for the Fluvial Landforms Observed}

[67] Did canyons form after valleys, or did they form at the same time? This question is key to understanding the processes that formed these features. The results from the HRSC DEM show that most small valleys follow pathways connected with canyon tributaries, showing that these connections are likely not a coincidence (Figure 17). Potentially, canyons could have been created from the topography created by pre-existing small valleys. Such an evolution could explain why some cut valleys on the plateau (Figure 4a). However, this does not account for most canyons. Valleys are shallow $(<80 \mathrm{~m})$ compared to canyons, so it is not likely that sapping processes would use preexisting valley topography. It is also important to remember that sapping processes require groundwater recharge by precipitation [Laity and Malin, 1985]. If small valleys formed first, independently from canyons, and the recharge occurred later, we would expect to see the erosional effect of this recharge on the weak upper layer. Potentially this erosion might be visible as the small valleys found on the plateau, and therefore would explain their connections to canyon heads. A point against such a coeval evolution would be that canyon wallslopes do not show any sign of water erosion. This is not contrary to valley formation. Since canyons have steep slopes $\left(>25^{\circ}\right)$ they had a long history of dry mass wasting with slope erosion that would have removed any older evidence of erosion. Thus we suggest that the formation of valleys on the plateau is more or less contemporary to the formation of the tributary canyons, with a few canyons finishing their formation after the latest overland flow episodes.

[68] Differences in lithology play a strong role in the development of landforms. We observe in both the MOC and HRSC images that a thin unit $(\approx 100-150$ m thick) of slightly indurated material lies over the plateau above the basement rocks. This could represent a erosional weak unit that could be easily incised. This layer, possibly ash deposits or compacted aeolian fines, might also behave as a relatively impermeable layer if composed of fine-grained compacted materials. Typical permeability of fine-grained materials (silt or clay size) is on the order of $10^{-4}$ to 1 Darcy [e.g., Freeze and Cherry, 1979]. Below this layer we observe the top of a strong unit, probably composed of stacks of lava flows. Lavas have typical permeabilities of $10^{-2}$ to $10^{4}$ Darcies [e.g., Freeze and Cherry, 1979], but the largest values are valid for the permeability at the macro- 
scopic scale only. Manga [2004] estimates that the permeability of a crust containing mainly basaltic lavas is of the range of $10^{3}$ Darcies. A permeability ratio of up to 1 million between fine-grained deposits and lavas is possible, generating strong differences in the type of fluvial flows.

[69] We propose the following evolutionary scenario to explain our observations (Figure 22).

[70] Dark weak homogeneous material covers the plateau. Fluvial events then begin and create small valleys into this upper unit. The low permeability of the upper unit favors runoff and limits infiltration.

[71] After some period of fluvial erosion, the main valleys erode the upper unit reaching the basement. The stronger resistance to erosion of the basement modifies the type of erosion for these main valleys, forming the wide and flat valleys exposing the basement at surface. While runoff continues everywhere, infiltration is enhanced below these wide and flat valleys compared to surrounding terrains, because of the higher permeability of the lava flows.

[72] Canyons begin to form by the combined effect of runoff and sapping. If overland flows are strong enough, they might initiate canyons formation at the outlet of main wide and flat valleys. The enhanced infiltration below these wide valleys enables a backward recession by sapping at the outlet of these landforms. In the final stage, runoff ceases and sapping continues explaining the occurrence of canyons that locally cut valleys on the plateau.

[73] After this period of fluvial erosion the aqueous processes ceased and valley networks were preserved in their current geometry. Subsequent aeolian processes modified this landscape, explaining why some valleys are poorly preserved while some others, which had alluvial deposits on their floor, are inverted.

[74] Debates exist on the respective role of runoff and sapping in the formation of Martian valleys [e.g., Craddock and Howard, 2002; Harrison and Grimm, 2005]. The evolution model proposed explains the presence of three types of landforms, small valleys, wide and flat valleys and tributary canyons, in a single episode of fluvial erosion where the main physical difference in these features is controlled by lithology.

\subsection{Importance of Lithology and the Extent of Fluvial Landforms}

[75] Shallow valleys formed over the Echus plateau during the Late Hesperian period [Mangold et al., 2004] and possibly later [Fasset and Head, 2007]. This period has fewer fluvial networks than the Noachian period [e.g., Carr, 1996]. Shallow dendritic valleys are not observed over all Hesperian terrains, but they are observed on the northern plateau of Valles Marineris close to the Echus Chasma, Juventae Chasma and Ganges Chasma, as well as into the canyon in the Melas Chasma [Quantin et al., 2005]. This distribution might be due to local precipitation resulting from local climatic effects, and/or to regional heatflow that triggered snowmelt in specific regions, such as the source areas of the Chasmata. The latter would help explain the location of these fluvial landforms in connection with canyons (Echus, Juventae, Ganges). Although these hypotheses are possible, we propose additional effects due to factors intrinsic to valley formation: (1) the distribution of the weak upper unit, and (2) the preservation of this weak unit. (1) The
Echus Chasma case shows that overland flows form valleys better when a relatively weak layer is present at the top of lava flows. The lack of a weak upper unit would favor infiltration rather than surface runoff. Shallow valleys distribution are then dependent on the geographic distribution of deposits such as ash and/or fine aeolian deposits of loess type. (2) Fluvial erosion combined with the subsequent wind erosion that formed inverted channels locally, could have removed the $\approx 100 \mathrm{~m}$ of material from the surface, leaving only the fresh basement visible. As a result, only canyons that formed into the basement lavas can indicate a fluvial activity occurred. A planet-wide survey of fluvial relics, such as that begun by Williams [2007], should improve our knowledge of the distribution of valleys networks proposed in our study to better map their spatial and temporal extent.

[76] The high resistance and high permeability of the basement lava flows also have some consequences on the distribution of post-Noachian fluvial landforms. The Late Noachian and Early Hesperian is a period of widespread plain volcanism with creation of the Tharsis plateau and intercrater plains [e.g., Tanaka, 1986], which might have favored sapping processes. Noachian terrains were interpreted as some type of megaregolith with a large porosity and heavily fractures [MacKinnon and Tanaka, 1989; Clifford, 1993], which could also have favored sapping processes. However, recent findings show that Noachian terrains contain light toned layered material different from a porous megaregolith [Malin and Edgett, 2000; Loizeau et al., 2007] and that clay minerals are found extensively [Poulet et al., 2005; Mangold et al., 2007; Loizeau et al., 2007; Mustard et al., 2007]. Such an altered crust would be much less permeable than lava flows, implying that the Noachian crust might support surface runoff more easily than previously thought. Therefore the decrease of valleys development from Noachian to Hesperian periods, usually interpreted as a change in climate [e.g., Harrison and Grimm, 2005], could also be interpreted by differences in lithology: A possible approach might be to compare Hesperian lava plateaus with Noachian lava plateaus, rather than Noachian highlands terrain, or include new spectral data in these studies.

\subsection{Duration of Valleys Formation and Implications for Past Climatic Conditions}

[77] The period of shallow valley formation of the is difficult to estimate. Different parameters can help us to constrain this period quantitatively: (1) the $2 \mathrm{D}$ extension of the network, (2) the discharge rate (3) the total eroded volume and the depth of incision, and (4) longitudinal valley profiles.

[78] Dendritic patterns usually require $>1000$ years to develop to the point where the network has a large number of tributaries and a dense drainage density [Knighton, 1998]. After the network has reached a maximum density, we cannot know the duration of subsequent fluvial activity. Therefore this method only gives a rough estimation of the minimum duration. For shorter periods of time, this means that the network remains partially developed inside the watershed with poor connectivity between valleys, it has low drainage density and large interfluves occur in several locations within the basin. The exact period of time to reach this extension depends on the nature of the substratum and the local climate. For example, tephra deposits observed in 
Hawaii are easily eroded under a relative wet climate. There, valleys formed a complex dendritic network with main valleys about $10 \mathrm{~m}$ deep within a period of 300 years [Craddock et al., 2006]. Glacial tills in Alberta, Canada, have been incised under a semiarid climate and they have formed since the last glacial maximum, about 10,000 years ago [Knighton, 1998]. Lava flows require more than 100,000 years to reach a maximum drainage density [e.g., Leopold et al., 1972]. From the broad extension of the small valleys into the weak upper unit, the drainage systems observed on the Echus Chasma plateau would suggest a minimum period of time of the range of several thousands of years. In contrast, the geometry of canyons corresponds to a very limited extension that never reached the maximum. This suggests that a duration of 100,000 years necessary for lava flow incision might be a possible maximum. However, terrestrial lava flows taken as examples are thinner, and the period to reach maximum extension for such a thick lava unit is not known.

[79] Discharge rates can only be measured from channel depths; however there are no inner channels found within the valleys. The lack of apparent inner channels might be due to their small size which, together with the lack of well developed braided channels typical of high discharge (with one possible exception on Figure 3d), implies low discharge rates.

[80] The total thickness of material eroded is not large. We assume this thickness to be of around $75 \mathrm{~m}$ on average, as discussed in section 5.5. The minimum period of time necessary to erode this material can be estimated by the ratio of sediment to water. Terrestrial overland flows usually display water:sediment ratio of about 100 to 1000, decreasing to 10 or below in the case of high discharge floods such as lahars [e.g., Howard, 1988]. As we expect from the lack of inner channels a relative low discharge rate, we can assume a water:sediment ratio of about 100 . Using this ratio, the total volume of water that would have eroded the shallow valleys would be about 100 times the eroded thickness. In other words, the erosion of $75 \mathrm{~m}$ of the upper unit would require about $7.5 \mathrm{~km}$ of water column dropped in the system to get the observed landscape. This amount of water requires recycling of water over a given duration. A $1 \mathrm{~m} /$ year of precipitation, as rainfall or snow, is a typical value in temperate climate on Earth, can correspond to a reasonable maximum for Mars. The total amount of water of $7.5 \mathrm{~km}$ required would then correspond to duration of 7500 years to explain the observed eroded volume. Again, this is a rough calculation, which gives a minimum period of time. However, this minimum is consistent with the estimation obtained by evaluating the drainage density.

[81] The longitudinal profiles of most shallow valleys are straight, with few expressions of concavity. This indicates a short-term of valley network formation and their equilibrium was never reached. This information is difficult to relate to the duration of activity, but it probably precludes any longterm evolution $(>1 \mathrm{Ma}$ ) otherwise the longitudinal profiles would not reflect the regional slopes so closely and the canyons would be more developed.

[82] Mangold et al. [2004] studied the geometry of these fluvial landforms using $100 \mathrm{~m}$ sampled THEMIS images. From the drainage density and the network development they concluded that a minimum period of fluvial activity on the order of 10,000 years is necessary to form shallow valleys. However, this result could not help to discriminate if they formed either by geologically short episode(s) of that duration, or sustained long term evolution. The observations and measurements presented here confirm the minimum period previously proposed, but they favor geologically short term episode(s), rather than any sustained activity over millions of years. Even though the period of formation might be geologically short, such as 10,000 years, it requires significant surface flows and stable liquid water during that period. Fluvial systems with possible episodic lakes have been described in the Hesperian period [Ori et al., 2000; Quantin et al., 2005; Di Achille et al., 2006; Mangold and Ansan, 2006]. Hesperian fluvial activity is interpreted to have reactivated valleys in Noachian terrains [e.g., Baker and Partridge, 1986; Baker, 1988]. Valles Marineris canyons contain layered deposits composed of sulfates and oxides suggesting aqueous episodes after the Chasma opening in the Late Hesperian [Gendrin et al., 2005; Mangold et al., 2006]. Different hypotheses have been proposed to develop the late climate change in the Hesperian period, such as impact process [Segura et al., 2002], obliquity variations [Toon et al., 1980], or degassing due to the volcanism [Bibring et al., 2006] and the climate consequences of a sulfur-rich atmosphere [Johnson et al., 2007]. In any one of these cases, shallow valleys on the Valles Marineris plateau would be a direct consequence of the climate modifications that was episodically wet enough to trigger their formation. An alternative hypothesis is that the climatic episode preserved in the Echus plateau is somehow related to outflow channel formation. In such an hypothesis, the water vapor pressure may have increased suddenly consequently as a consequence of outflow channel formation, which might be related to an increase of the geothermal flux or magmatic activity [Baker et al., 1991]. The attractive aspect of this hypothesis is that it seems to fit the chronological and geographical relationships between valleys and the Echus Chasma and its tributary canyons. This model is currently under tests by climate models calculations [Santiago et al., 2006]. However, current models do not explain how recharge of the groundwater occurred, which is probably necessary to produce the large outflow channels.

\section{Conclusions}

[83] Our observations and measurements lead to the following conclusions.

[84] 1. The HRSC images confirm the identification of the branching valleys of the Echus Chasma plateau and reveal new valleys over a broader area. Valleys are shallow and show dendritic and sinuous patterns without widespread braided patterns. This suggests low discharge rates typical of fluvial valleys formed by overland flows rather than massive seepage or glacial surges.

[85] 2. The erosion of shallow valleys occurred within a dark unit that overlies the plateau basement and has a thickness $<150 \mathrm{~m}$. This unit is either less indurated or composed of finer grains than the basement as indicated by the thermal data. Sinuous lineations observed north of the Echus plateau and on the Juventae plateau likely correspond to a relief inversion due to differential erosion of the weak material overlying the plateau. 
[86] 3. Shallow valleys developed well into the upper unit because of its weak resistance to erosion. Shallow valleys follow the current topography and their heads are distributed along watershed boundaries. They are typically a few tens of meters deep and display a V-shaped transverse profile, but their longitudinal profiles suggest a limited period of formation that did not reached equilibrium.

[87] 4. Tributary canyons in Echus Chasma region cross shallow valleys in places. They incise into resistant basement unit and behave as sapping canyons. The connections between shallow valleys, wide and flat valleys that reach the basement and the heads of tributary canyons, as well as the 3D analysis of HRSC data, suggest that the evolution of these three landforms occurred coevally. The difference in erosion and permeability of the two units (upper weak layer and lava plateau beneath) might explain the morphologic differences in these fluvial features. In general, our study shows the importance of lithology in the development of fluvial landforms, which is a parameter that should be taken into account in the future studies of Martian valleys.

[88] 5. Our analyses suggest that fluvial erosion occurred over thousands of years as a minimum, with activity likely limited to periods shorter than millions of years. The occurrence of such fluvial activity is not as local as previously expected with examples found throughout the whole Valles Marineris region. It should be interesting to link these landforms to the alteration minerals found using spectral data at the surface of Mars: altered glasses found in Juventae Chasma plateau layered deposits [Milliken et al., 2007] could confirm the interest for these landforms as being indicators of a period of surface liquid water activity late in the early Mars history.

[89] Acknowledgments. We are grateful to the two reviewers, Bob Craddock and Keith Harrison, for their very constructive reviews. We acknowledge the effort of the HRSC Coinvestigator Team members and their associates who have contributed to this investigation in the preparatory phase and in scientific discussions within the teams, and especially E. Hauber, F. Scholten, and the photogrammetry group. We acknowledge the MOC/MGS and THEMIS/Odyssey teams for the availability of their data on the respective web pages at msss.com $/ \mathrm{mgs} / \mathrm{moc}$ and themis-data. asu.edu. The Programme National de Planétologie (PNP) of Institut National des Sciences de l'Univers (INSU-CNRS) and the Centre National d'Etude Spatial (CNES) granted French authors.

\section{References}

Allen, P. A. (1997), Earth Surface Processes, 404 pp., Blackwell Sci., Malden, Mass.

Ansan, V., and N. Mangold (2006), New observations of Warrego Valles, Mars: Evidence for precipitation and surface runoff, Planet. Space. Sci., $54,219-242$

Ansan, V., N. Mangold, Ph. Masson, and G. Neukum (2007), Topography of valley networks on Mars: Comparison between HRSC DEMs and MOLA data, 38th Lunar Planet. Sci. Conf., Abstract \#1660.

Ansan, V., N. Mangold, Ph. Masson, and G. Neukum (2008), Topography of valley networks on Mars from Mars Express High Resolution Stereo Camera digital elevation models, J. Geophys. Res., 113, E07006, doi:10.1029/2007JE002986, 15 July.

Baker, V. R. (1988), Evolution of small valley networks in the heavily cratered terrains of Mars, in Sapping Features of the Colorado Plateau, edited by A. D. Howard, R. C. Kochel, and H. E. Holt , NASA SP-491, 94-95, USA.

Baker, V. R. (2001), Water and the Martian landscape, Nature, 412, 228 236.

Baker, V. R., and J. B. Partridge (1986), Small Martian valleys: Pristine and degraded morphology, J. Geophys. Res., 91(B3), 3561-3572.

Baker, V. R., R. G. Strom, V. C. Gulick, J. S. Kargel, G. Komatsu, and V. S. Kale (1991), Ancient oceans, ice sheets and the hydrological cycle on Mars, Nature, 352, 589-594.
Bennett, M. R., and N. F. Glasser (1996), Glacial Geology, Ice Sheets and Landforms, 364 pp., John Wiley, Chichester, U.K.

Bibring, J.-P., Y. Langevin, J. F. Mustard, F. Poulet, R. Arvidson, A. Gendrin, B. Gondet, N. Mangold, P. Pinet, and F. Forget (2006), Global mineralogical and aqueous Mars history derived from OMEGA/Mars express data, Science, 312(2772), 400-404.

Brakenridge, G. R., H. E. Newson, and V. R. Baker (1985), Ancient hot springs on Mars: Origins and paleoenvironmental significance of small Martian valleys, Geology, 13(12), 859-862.

Carr, M. H. (1996), Water on Mars, 229 pp., Oxford Univ. Press, New York. Carr, M. H., and F. C. Chuang (1997), Martian drainage densities, J. Geophys. Res., 102, 9145-9152.

Carr, M. H., and J. W. Head III (2003), Basal melting of snow on early Mars: A possible origin of some valley networks, Geophys. Res. Lett., 30(24), 2245, doi:10.1029/2003GL018575.

Christensen, P. R., et al. (2003), Morphology and composition of the surface of Lars: Mars Odyssey THEMIS results, Science, 300, 2056-2062. Clifford, S. M. (1993), A model for the hydrologic and climatic behavior of water on Mars, J. Geophys. Res., 98, 10,973-11,016.

Costard, F., F. Forget, N. Mangold, and J. P. Peulvast (2002), Formation of recent Martian debris flows by melting of near-surface ground ice at high obliquity, Science, 295, 110-113.

Craddock, R. A., and A. D. Howard (2002), The case for rainfall on a warm, wet early Mars, J. Geophys. Res., 107(E11), 5111, doi:10.1029 2001JE001505.

Craddock, R. A., R. P. Irwin, R. Williams, D. Swanson, A. D. Howard, C. Quantin, and J. R. Zimbelman (2006), Topical Martian field studies in the Ka'U desert, Hawaii, 37th Lunar Planet. Sci. Conf., Abstract \#1384. Di Achille, G., G. G. Ori, D. Reiss, E. Hauber, K. Gwinner, G. Michael, and G. Neukum (2006), A steep fan at Coprates Catena, Valles Marineris, Mars, as seen by HRSC data, Geophys. Res. Lett., 33, L07204, doi:10.1029/2005GL025435.

Dohm, J. M., and K. L. Tanaka (1999), Geology of the Thaumasia region, Mars, Planet. Space Sci., 47, 411-431.

Duxbury, T. C., R. L. Kirk, B. A. Archibal, and G. A. Neumann (1999), Mars geodesy/cartography working group recommendation on Mars cartographic constants and coordinate systems, Symp. on Geospatial Theory, Processing, and Appl., Ottawa.

Fasset, C. I., and J. W. Head (2006), Valleys on Hecates Tholus, Mars: Origin by basal melting of summit snowpack, Planet. Space Sci., 54, $370-378$.

Fasset, C. I. and J. W. Head III (2007), Direct constraints on the timing of Martian valley network formation derived using buffered crater counting, in 7th International Conference on Mars (2007), Pasadena, Abstract \#3050.

Forget, F., R. M. Haberle, F. Montmessin, B. Levrard, and J. W. Head (2006), Formation of glaciers on Mars by atmospheric precipitation at high obliquity, Science, 311, 368-371.

Forsythe, R. D., and C. R. Clyde (1998), Closed drainage crater basins of the Martian highlands: Constraints on the early Martian hydrologic cycle, J. Geophys. Res., 103, 31,421-31,431.

Freeze, R. A., and J. A. Cherry (1979), Groundwater, 604 pp., PrenticeHall, Upper Saddle River, N. J.

Gendrin, A., et al. (2005), Sulfates in Martian layered terrains: The OMEGA/ Mars Express view, Science, 307, 1587-1591.

Grant, J. A. (2000), Valley formation in Margaritifer Sinus, Mars, by precipitation-recharged groundwater sapping, Geology, 28(3), 223-226.

Gulick, V. C. (2001), Origin of the valley networks on Mars: A hydrological perspective, Geomorphology, 241-268.

Gulick, V. C., and V. R. Baker (1989), Fluvial valleys and martian palaeoclimates, Nature, 341, 514-516.

Gwinner, K. F. Scholten, B. Gise, J. Oberst, R. Jaumann, R. Spiegel, R. Schmidt, and G. Neukum (2005), Hochauflösende Digitale Geländemodelle der Marsoberfläche auf der Grundlage von Mars Express HRSC daten, Photogrammetrie Fernerkundung Geoinformation (PFG) 5/2005, S387-394, Germany.

Harrison, K. P., and R. E. Grimm (2005), Groundwater controlled valley networks and the decline of surface runoff on early Mars, J. Geophys. Res., 110, E12S16, doi:10.1029/2005JE002455.

Head, J. W., and D. R. Marchant (2003), Cold-based mountain glaciers on Mars: Western Arsia Mons, Geology, 31(7), 641-644.

Head, J. W., M. A. Kreslavsky, and M. Pratt (2002), Northern lowlands of Mars: Evidence for widespread volcanic flooding and tectonic deformation in the Hesperian period, J. Geophys. Res., 107(E1), 5003, doi:10.1029/ 2000JE001445.

Higgins, C. G. (1982), Drainage systems developed by sapping on Earth and Mars, Geology, 10, 147-152.

Horton, R. E. (1945), Erosional development of streams and their drainage basins: Hydrophysical approach to quantitative morphology, Geol. Soc. Am. Bull., 82, 1355-1376. 
Howard, A. D. (1988), Introduction: Groundwater sapping on Mars and Earth, in Sapping Features of the Colorado Plateau, edited by A. D. Howard, R. C. Kochel, and H. E. Holt, NASA SP-491, pp. 1-5, USA.

Irwin, R. P., A. D. Howard, and R. A. Craddock (2006), Theater-headed valleys: The roles of overland flow and groundwater sapping, 37th Lunar Planet. Sci. Conf., Houston, Abstract \#1912.

Johnson, S. S., M. T. Zuber, T. L. Grove, A. A. Pavlov, and M. A. Mischna (2007), Sulfur Volatiles in the Early Martian Atmosphere, 38th Lunar Planet. Sci. Conf., Abstract \#1754.

Kargel, J. S., and R. G. Strom (1992), Ancient glaciations on Mars, Geology, 20(1), 3-7.

Knighton, D. (1998), Fluvial Forms and Processes: A New Perspective, 383 pp., Oxford Univ. Press, New York.

Kochel, R. C. (1988), Role of groundwater sapping in the development of large valley networks on Hawaii, in Sapping Features of the Colorado Plateau, edited by A. D. Howard, R. C. Kochel, and H. E. Holt, NASA SP-491, pp. 100-101, USA.

Kochel, R. C., D. W. Simmonds and J. F. Piper (1988), Groundwater sapping experiments in weakly consolidated layered sediments: a qualitative summary, in Sapping Features of the Colorado Plateau, edited by A. D. Howard, R. C. Kochel, and H. E. Holt, NASA SP-491, pp. 84-93.

Laity, J. E. (1988), The role of groundwater sapping in valley evolution on the Colorado plateau, in Sapping Features of the Colorado Plateau, edited by A. D. Howard, R. C. Kochel, and H. E. Holt, NASA SP-491, pp. $63-70$, USA

Laity, J. E., and M. C. Malin (1985), Sapping processes and the development of theater-headed valley networks in the Colorado plateau, Geol. Soc. Am. Bull., 96, 203-217.

Lamb, M. P., and W. E. Dietrich (2004), Groundwater sapping as potential mechanism for the formation of a theater-headed basaltic canyon, Box Canyon, Idaho, Workshop on Martian Valley Networks, Kona, Hawaii, USA.

Lamb, M. P., A. D. Howard, J. Johnson, K. X. Whipple, W. E. Dietrich, and J. T. Perron (2006), Can springs cut canyons into rock?, J. Geophys. Res., 111, E07002, doi:10.1029/2005JE002663.

Lamb, M. P., A. D. Howard, W. E. Dietrich, and J. T. Perron (2007), Formation of amphitheater-headed valleys by waterfall erosion after large-scale slumping on Hawaii, Geo. Soc. Am. Bull., 119(7/8), 805-822.

Leopold, L. B., M. G. Wolman and J. P. Miller (1972), Fluvial Processes in Geomorphology, 520 pp., Dover, Mineola, N. Y.

Loesch, T. N. (2001), Hydrologic Analysis Using GIS. Minnesota GIS/LIS Consortium, Spring Workshop, Alexandria, Minnesota, USA.

Loizeau, D., et al. (2007), Phyllosilicates in Mawrth Vallis region, Mars, J. Geophys. Res., 112, E08S08, doi:10.1029/2006JE002877.

Lucchitta, B. K. (2005), Light layers and sinuous ridges on plateau near Juventae Chasma, Mars, 36th Lunar Planet. Sci. Conf., Houston, Abstract \#1500

Lucchitta, B. K., A. McEwen, G. D. Clow, P. E. Geissler, R. B. Singer, R. A. Schultz, and S. W. Squyres (1992), The canyon system on Mars, in Mars, edited by H. H. Kieffer et al., pp. 453-492, Univ. Arizona Press, Tucson.

MacKinnon, D. J., and K. L. Tanaka (1989), The impacted Martian crust: Structure, hydrology, and some geologic implications, J. Geophys. Res. 94, 17,359-17,370.

Maizels, J. K. (1990), Raised channels system as indicators of paleohydrological change: A case study in Oman, Paleogeogr. Paleoclimatol. Paleoecol., 76, 241-277.

Malin, M. C., and K. S. Edgett (2000), Sedimentary rocks of early Mars, Science, 290, 1927-1937.

Malin, M. C., and K. S. Edgett (2003), Evidence for persistent flow and aqueous sedimentation on Early Mars, Science, 302, 1931-1934.

Manga, M. (2004), Martian floods at Cerberus Fossae can be produced by groundwater discharge, Geophys. Res. Lett., 31, L02702, doi:10.1029/ 2003GL018958.

Mangold, N., C. Quantin, V. Ansan, C. Delacourt, and P. Allemand (2004), Evidence for precipitation on Mars from dendritic valleys in the Valles Marineris area, Science, 305(5680), 78-81.

Mangold, N., and V. Ansan (2006), Detailed study of an hydrological system of valleys, a delta and lakes in the Southwest Thaumasia region, Mars, Icarus, 180, 75-87.

Mangold, N., A. Gendrin, C. Quantin, B. Gondet, J.-P. Bibring (2006), Sulfate deposits and geology of West Candor Chasma, A case study, Workshop Martian Sulfates as Recorders of Atmospheric-Fluid-Rock Interactions, Houston, Clear Lake, \#7039, Lunar Planet Inst., Houston.

Mangold, N., et al. (2007), Mineralogy of the Nili Fossae region with OMEGA/MEx data: 2. Aqueous alteration of the crust, J. Geophys. Res., 112, E08S04, doi:10.1029/2006JE002835.

Mikovsky, J. C., J. L. Saos, and A. Bonkel (1991), Paleohydrology and paleoclimatology of closed basins in south Mauritania since 18,000 BP, Bull. Soc. Geol. France, 162(6), 1141-1150.

Milkovich, S. M., J. W. Head III, and S. Pratt (2002), Meltback of
Hesperian-aged ice-rich deposits near the south pole of Mars: Evidence for drainage channels and lakes, J. Geophys. Res., 107(E6), 5043 , doi:10.1029/2001JE001802.

Milliken, R. E., G. Swayze, S. Murchie, J. Bishop, R. Clark, B. Ehlmann, J. Grotzinger, J. Mustard, and C. Weitz (2007), Spectral evidence for aqueous alteration of the plains surrounding Valles Marineris, Mars, AGU Fall Meeting, San Francisco, Abstract P12A-02.

Mustard, J. F., et al. (2007), New insights into hydrated silicate minerals observed on Mars by OMEGA and CRISM, 2nd Mars Express Conference, ESTEC, Holland.

Neukum, G., and R. Jaumann (2004), HRSC: the High Resolution Stereo Camera of Mars Express, in Mars Express: The Scientific Payload, edited by A. Wilson, pp. 17-35, ESA SP-1240, Noordwijk, Netherlands.

Ori, G. G., L. Marinangelli, and A. Baliva (2000), Terraces and Gilbert-type deltas in crater lakes in Ismenius Lacus and Memnonia, Mars, J. Geophys. Res., 105(E7), 17,629-17,641.

Pain, C. F., and C. D. Ollier (1995), Inversion of relief, a component of landscape evolution, Geomorphology, 46, 151-165.

Pain, C. F., J. D. A. Clarke, and M. Thomas (2007), Inversion of relief on Mars, Icarus, 190(2), 478-491, October

Phillips, L. O., and S. A. Schumm (1987), Effect of regional slope on drainage networks, Geology, 15, 813-816.

Pieri, D. C. (1986), Martian Valleys: Morphology, distribution, age, and origin, Science, 210, 4472, 895-897.

Pollack, J. B., J. F. Kasting, S. M. Richardson, and K. Poliakoff (1987), The case for a wet and warm climate on early Mars, Icarus, 71, 203-224.

Poulet, F., J.-P. Bibring, J. F. Mustard, A. Gendrin, N. Mangold, Y. Langevin, R. E. Arvidson, B. Gondet, and C. Gomez (2005), Phyllosilicates on Mars and implications for early Martian climate, Nature, 438, 623-627.

Putzig, M. E., M. T. Mellon, K. A. Kretke, and R. E. Arvidson (2005) Global thermal inertia and surface properties of Mars from the MGS mapping mission, Icarus, 173(2), 325-341.

Quantin, C., P. Allemand, N. Mangold, G. Dromart, and C. Delacourt (2005), Fluvial and lacustrine activity on layered deposits in Melas Chasma, Valles Marineris, Mars, J. Geophys. Res., 110, E12S19, doi:10.1029/2005JE002440.

Santiago, D. L., A. Colaprete, R. M. Haberle, L. C. Sloan, and E. I. Asphaug (2006), Clouds, cap, and consequences: Outflow events and Mars Hesperian climate, 37th Lunar Planet, Sci. Conf., Houston, Abstract \#1484.

Scholten, F., K. Gwinner, T. Roasch, K. D. Matz, M. Wählisch, B. Giese, J. Oberst, R. Jaumann, and G. Neukum (2005), Mars Express HRSC data processing, Photogramm. Eng. Remote Sens., 71, 1143-1152.

Schumm, S. A., M. P. Mosley, and W. E. Weaver (1987), Experimental Fluvial Geomorphology, 413 pp., John Wiley, New York.

Scott, D. H., and K. L. Tanaka (1986), Geologic map of the western equatorial region of Mars, USGS Misc. Inv. Ser. Map I-1802-A, USGS, Flagstaff.

Segura, L., O. B. Toon, A. Colaprete, and K. Zahnle (2002), Environmental effects of large impact craters on Mars, Science, 298(5600), 1977-1980. Stearns, H. T. (1966), Geology of the State of Hawaii, Calif. Pacific Books, Palo Alto, Calif.

Stepinski, T. F., M. L. Collier, P. J. McGovern, and S. M. Clifford (2004), Martian geomorphology from fractal analysis of drainage networks, J. Geophys. Res., 109, E02005, doi:10.1029/2003JE002098.

Strahler, A. N. (1952), Dynamic basis of geomorphology, Geol. Soc. Am. Bull., 63, 923-938.

Tanaka, K. L. (1986), The stratigraphy of Mars. Proceedings of the Lunar Planetary Science, vol. 17, J. Geophys. Res., 91, E139-E158.

Toon, O. B., J. B. Pollack, W. Ward, J. A. Burns, and K. Bilski (1980), The astronomical theory of climate change on Mars, Icarus, 44, 552-607.

Williams, R. S. (1978), Geomorphic processes in Iceland and on Mars; a comparative appraisal from orbital images, Geol. Soc. Am. Abstr., 1(7), 517.

Williams, R. M. E. (2007), Global Spatial distribution of raised curvilinear features on Mars, 38th Lunar Planet. Sci. Conf., Abstract \#1821.

Williams, R. M. E., and K. S. Edgett (2005), Valleys in the Martian rock record, 36th Lunar Planet. Sci. Conf., Abstract \#1099.

Wise, D. U., M. P. Golombek, and G. E. McGill (1978), Tharsis Province of Mars: Deformational history and fault sequence. Reports of planetary geology program, NASA, 203-204

Withers, P., and G. A. Neumann (2001), Enigmatic northern plains of Mars, Nature, 410, 651

V. Ansan, N. Mangold, and Ph. Masson, Laboratoire IDES UMR 8148, Université Paris-Sud and CNRS, Batiment 509, 91405 Orsay, France. (nicolas.mangold@u-psud.fr)

G. Neukum, Freie Universität, Berlin, Germany.

C. Quantin, Laboratoire Science de la Terre, UMR5570 UCB et ENS Lyon, 6922 Villeurbanne, France. 